\title{
CAIX forms a transport metabolon with monocarboxylate transporters in human breast
} cancer cells

\author{
Samantha Ames ${ }^{1}$, Jacob T. Andring ${ }^{2}$, Robert McKenna ${ }^{2}$, Holger M. Becker ${ }^{1,3,}$ \\ ${ }^{1}$ Division of General Zoology, Department of Biology, University of Kaiserslautern (TUK), D-67653 \\ Kaiserslautern, Germany; ${ }^{2}$ Department of Biochemistry and Molecular Biology, University of Florida, \\ Gainesville, Florida 32610; Institute of Physiological Chemistry, University of Veterinary Medicine \\ Hannover, D-30559 Hannover, Germany \\ *Correspondence to: Holger M. Becker (Holger.Becker@tiho-hannover.de)
}

Running Title: CAIX forms a transport metabolon with MCTs

\begin{abstract}
Tumor cells rely on glycolysis to meet their elevated demand for energy. Thereby they produce significant amounts of lactate and protons, which are exported via monocarboxylate transporters (MCTs), supporting the formation of an acidic microenvironment. The present study demonstrates that carbonic anhydrase IX (CAIX), one of the major acid/base regulators in cancer cells, forms a protein complex with MCT1 and MCT4 in tissue samples from human breast cancer patients, but not healthy breast tissue. Formation of this transport metabolon requires binding of CAIX to the Ig1 domain of the MCT1/4 chaperon CD147 and is required for CAIX-mediated facilitation of MCT1/4 activity. Application of an antibody, directed against the CD147-Ig1 domain, displaces CAIX from the transporter and suppresses CAIX-mediated facilitation of proton-coupled lactate transport. In cancer cells, this "metabolon disruption" results in a decrease in lactate transport, reduced glycolysis and ultimately reduced cell proliferation. Taken together, the study shows that carbonic anhydrases form transport metabolons with acid/base transporters in human tumor tissue and that these interactions can be exploited to interfere with tumor metabolism and proliferation.
\end{abstract}

Key words: Carbonic anhydrase IX, in situ proximity ligation assay, metabolon disruption, tissue micro array, lactate imaging 


\section{Introduction}

Despite substantial progress in early detection and tumor therapy, breast cancer is still the most commonly diagnosed form of cancer and leading cause of cancer death in women worldwide [1]. Like most solid tumors, breast tumor tissue displays a significant increase in glycolytic activity, as compared to healthy breast tissue [2]). This increase in glycolysis, which was discovered by Otto Warburg more than 90 years ago [3, 4], is now considered an emerging hallmark of cancer [5]. Glycolytic activity results in the production of lactate and protons, which have to be removed from the cell to avoid intracellular acidosis and suffocation of metabolism. Lactate flux in cancer cells is primarily mediated by the monocarboxylate transporters MCT1 and MCT4, both of which transport lactate together with $\mathrm{H}^{+}$in an electroneutral 1:1 stoichiometry [6-9]. MCT1, which is ubiquitously expressed in most tissue, has a $\mathrm{K}_{\mathrm{m}}$ value of 3-5 $\mathrm{mM}$ for lactate $[6,7]$ and mediates both influx and efflux of lactate and protons, depending on the cell's metabolic profile. MCT4 is considered a highcapacity carrier with a $\mathrm{K}_{\mathrm{m}}$ value of 20-35 mM for lactate [8], which primarily acts as a lactate exporter in glycolytic cells, including hypoxic cancer cells. Expression of both MCT1 and MCT4 is increased in breast cancer tissue, as compared to healthy breast epithelium, and correlates with increasing tumor grade [10-15]. Furthermore, expression of MCT1 was shown to correlate with shorter progressionfree survival and increased risk of recurrence after chemotherapy in breast cancer patients $[2,10]$. In cultured breast cancer cells, knockdown of MCT1 and MCT4, decreases proliferation, migration and invasion [16]. These finding indicate that $\mathrm{MCT}$-mediated lactate/ $\mathrm{H}^{+}$cotransport contributes to cancer cell aggressiveness.

Trafficking of the MCT proteins to the plasma membrane, but also regulation of transport function, is mediated by ancillary proteins. For MCT1 and MCT4 the preferred ancillary protein is CD147 which is tightly associated with the transporter in the membrane [17-19]. The general isoform of CD147 (termed CD147-Ig1-Ig2, basigin or basigin-1), which is ubiquitously expressed in most tissue, comprises two extracellular, immunoglobulin (Ig)-like domains, a transmembrane domain and a short intracellular C-terminal tail [20,21]. CD147 is a multifunctional protein, which has been attributed a key role in the development and progression of different tumor types, including breast cancer. CD147 was shown to induce surface expression of matrix metalloproteases in adjacent tumor cells or fibroblast and has therefore been attributed a function in tumor cell invasion [22, 23]. Furthermore, CD147 can induce expression of vascular endothelial growth factors (VEGF) and production of hyaluronan to stimulate angiogenesis [22]. CD147 interacts with the multidrug resistance transporter MDR1 and vacuolar $\mathrm{H}^{+}$-ATPase, thereby promoting chemoresistance [24, 25]. Immunohistological staining demonstrated that expression of CD147 is upregulated in breast cancer tissue, as compared to normal breast tissue [10]. Similar to the expression of MCT1 and MCT4, expression levels of CD147 increase with increasing histological grade $[10,15]$ and positively correlate with poor prognosis and chemoresistance in breast cancer patients $[10,23,25]$.

Transport activity of MCTs can be facilitated by carbonic anhydrase IX (CAIX), an enzyme that has been attributed a central role in tumor acid/base regulation and cancer progression [26-30]. CAIX is tethered to the extracellular face of the plasma membrane via a transmembrane domain. Like the other isoforms of carbonic anhydrase, catalytic activity of CAIX is supported by an intramolecular proton shuttle, which mediates the rapid exchange of $\mathrm{H}^{+}$between the enzyme's catalytic center and the surrounding bulk solution. Unlike the other carbonic anhydrases however, CAIX features a 59 amino acid long proteoglycan-like (PG) domain, which is unique to CAIX within the CA family [28]. In healthy tissue, expression of CAIX, which is under control of the hypoxia-inducible factor HIF-1 $\alpha$ [31], is restricted to intestine and gall bladder [32]. However, CAIX is upregulated in many different 
tumor types, including breast cancer [33, 34]. Expression levels of CAIX positively correlate with histological tumor grade in breast cancer [12-14, 34-40]. Furthermore, expression of CAIX was found to correlate with reduced overall survival and higher occurrence of relapse and is associated with chemoresistance in breast cancer patients [34, 41, 42]. Interestingly, expression of CAIX was also found to correlate with MCT1 and CD147 in breast tumor tissue [34].

CAIX physically and functionally interacts with various acid/base transporters in tumor cells. CAIX was shown to colocalize with the $\mathrm{Na}^{+} / \mathrm{HCO}_{3}{ }^{-}$cotransporter $\mathrm{NBCe} 1$ and the $\mathrm{Cl} / \mathrm{HCO}_{3}{ }^{-}$exchanger AE2 in the lamellipodia of migrating SiHa cells [43]. Therefore it was suggested that CAIX can form a "transport metabolon" with NBCe1 and AE2 to facilitate $\mathrm{HCO}_{3}^{-}$flux across the cell membrane and drive cell migration [43]. A "transport metabolon" is defined as a structural and functional complex, composed of a transport protein and an enzyme, which interact with each other to facilitate substrate transport across the cell membrane. Transport metabolons are formed from various intracellular and extracellular carbonic anhydrases and acid/base transporters, including $\mathrm{Na}^{+} / \mathrm{H}^{+}$-exchangers (NHEs), AEs, NBCs, and MCTs (for review see [44-47]. We have previously shown that CAIX facilitates MCT transport activity in cultured breast cancer cells and when heterologously coexpressed in Xenopus oocytes, by a mechanism that is independent from the CA's catalytic function [29, 30]. In the present study, we investigate whether CAIX forms a transport metabolon with MCT1 and MCT4 in human breast cancer tissue and analyze the structural components that mediate the formation of this protein complex. Furthermore, we elaborate whether the MCT1/4-CAIX transport metabolon can be exploited as drug target for tumor therapy.

\section{Results}

\section{CAIX interacts with MCT1 and MCT4 in human breast cancer cells}

Lactate efflux from cancer cells is primarily mediated by the monocarboxylate transporters MCT1 and MCT4 [10, 11, 48], the activity of which has been shown to be facilitated by CAIX, which functions as proton antenna for the transporter $[29,30]$. In order to establish an efficient proton transfer, enzyme and transporter have to be localized in close proximity to each other. To investigate whether CAIX forms such a "transport metabolon" with MCTs in human breast cancer tissue, we first analyzed the physical interaction between CAIX and MCT1/MCT4, using in situ proximity ligation assays (PLA). CAIX was found to interact with MCT1 in tumor tissue samples from human breast cancer patients (Figure $1 \mathrm{~A}-\mathrm{C}, \mathrm{E})$, but not in uninvolved breast tissue (Figure $1 \mathrm{D}, \mathrm{E})$. Interestingly, the number of protein complexes increased in samples from grade II and grade III tumors, as compared to grade I tumors. CAIX did also interact with MCT4 in the same set of tissue samples (Figure $2 \mathrm{~A}-\mathrm{C}, \mathrm{E}$ ), but not in uninvolved breast tissue (Figure $2 \mathrm{D}, \mathrm{E}$ ). While no significant changes in the number of protein complexes could be detected between grade I and grade II tumors, grade III tumors showed a significant increase in the number of MCT4-CAIX interactions. When MCT1 and MCT4 are considered together, the number of transport metabolons constantly increases with increasing tumor grade from 13 signals/cell in grade I, 20 signals/cell in grade II and 30 signals/cell in grade III tumors.

Expression of CAIX is controlled by the hypoxia-inducible factor, HIF-1 $\alpha$. Therefore, it appears likely that the MCT-CAIX transport metabolon will primarily form under hypoxic conditions. Indeed, the number of interactions between MCT1 and CAIX, as well as MCT4 and CAIX more than doubled in MDA-MB-231 breast cancer cells, incubated under hypoxia $\left(1 \% \mathrm{O}_{2}\right)$, as compared to normoxic cells (Figure $3 A_{1}, A_{2}, B_{1}, B_{2}, C, D$ ). In MCF-7 cells, hypoxia induced a more than threefold increase in MCT1CAIX interactions (Figure $4 A_{1}, A_{2}, B$ ). In both cell lines, knockdown of CAIX resulted in a significant 
decrease in the PLA signal, while omission of the primary antibodies resulted in no signal at all (Figure $3 A_{3}, A_{4}, B_{3}, B_{4}, C$, D; Figure $4 A_{3}, A_{4}, B$ ). In MCF-7 cells, which do not express MCT4 [29], no signals where observed when the assay was carried out with antibodies against MCT4 and CAIX (Figure $4 \mathrm{~B}$, right bar). Colocalization of MCT1/4 and CAIX could also be confirmed by conventional immune staining for MCT1, MCT4 and CAIX in MDA-MB-231 (Figure $3 E_{1}, E_{2}$ ) and MCF-7 cells (Figure $4 C_{1}, C_{2}$, $\mathrm{C}_{3}, \mathrm{C}_{4}$ ). Taken together, these results indicate that MCT1 and MCT4 can form a protein complex with CAIX in hypoxic breast cancer cells.

\section{CAIX binds to the Ig1 domain of the MCT1/4 chaperon CD147}

Direct interaction between MCT1/4 and CAIX requires binding between the proteins. We have recently shown that the extracellular CA isoform CAIV does not directly bind to MCT1 or MCT4, but to the Ig1 domain in the transporters' chaperon CD147 [49]. Binding of CAIX to CD147 was tested by pulldown of CAIX, heterologously expressed in Xenopus oocytes, with a GST fusion protein of the Ig1 domain of CD147 (Figure 5). Pulldown of CAIX with CD147-WT resulted in a robust signal for CAIX, indicating direct binding between the two proteins (Figure $5 \mathrm{C}, \mathrm{D}$ ). Molecular docking experiments suggested that binding between CD147 and CAIX is mediated by CD147-Glu73 (Figure $5 \mathrm{~A}_{1}$ ) and CAIXHis200 (Figure $5 A_{2}$ ). Indeed, mutation of Glu73 in the Ig1 domain of CD147 and His200 in the catalytic domain of CAIX resulted in a loss of interaction, while mutation of the adjacent Glu31 in the Ig1 domain of CD147 had no significant effect on binding (Figure 5 C, D). Equal expression of CAIX-WT and CAIX-H200A in Xenopus oocytes, used for the pulldown, was confirmed by western blot analysis (Figure 5 B). In summary, the pulldown shows that CAIX binds to the Ig1 domain of CD147, most likely by forming a hydrogen bond between CAIX-His200 and CD147-Glu73.

\section{CAIX-mediated facilitation of MCT transport activity requires binding of CAIX to CD147}

To investigate whether direct binding of CAIX to CD147 is required for CAIX-mediated facilitation of MCT transport activity, we coexpressed rat MCT1 together with rat CD147-WT or a mutant of the chaperon and CAIX in Xenopus oocytes (Figure 6 A). Coexpression of MCT1 and rCD147-WT with CAIX resulted in a significant increase in MCT1 transport activity, both in the direction of influx and efflux, as measured from the rate of change in intracellular $\mathrm{H}^{+}$concentration during application (Figure $6 \mathrm{C}$ ) and removal (Figure 6 D) of lactate. Mutation of rCD147-Lys73 (the analogue to hCD147-Glu73) resulted in a loss of functional interaction between MCT1 and CAIX, while mutation of rCD147-Glu32 (analogue to hCD147-Glu31) had no effect on CAIX-mediated facilitation in MCT1 activity (Figure $6 \mathrm{~A}$, C, D). Neither mutation of rCD147-Lys73 nor rCD147-Glu32 had any effect on MCT1 transport activity in the absence of CAIX (Figure $6 \mathrm{C}, \mathrm{D}$ ). Expression of CAIX was confirmed by a $\mathrm{CO}_{2}$ pulse the end of each experiment (Figure $6 \mathrm{~A}, \mathrm{~B}$ ). Extracellularly applied $\mathrm{CO}_{2}$ diffuses into the oocyte, where it is hydrated to $\mathrm{HCO}_{3}{ }^{-}$and $\mathrm{H}^{+}$, resulting in intracellular acidification. Since hydration of $\mathrm{CO}_{2}$ is catalyzed by CAIX, the rate of intracellular acidification provides a direct measure for CAIX catalytic activity. That CAIX-His200 is crucial for the functional interaction between MCT1 and CAIX was already confirmed in a previous study (see Figure 4 in [29]).

To confirm that binding of CAIX to rCD147 follows the same mechanism as observed for hCD147, CAIX was pulled down with a GST fusion protein of the Ig1 domain of rCD147-WT or a mutant of the protein (Figure 6 E, F). Pulldown of CAIX with rCD147-WT and rCD147-E32A resulted in a robust signal for CAIX, while pulldown with rCD147-K73A produced no signal for CAIX (Figure $6 \mathrm{~F}$ ). Pulldown of CAIX-H200A with rCD147-WT also resulted in no signal for CAIX in three out of four pulldowns. In one of the four pulldowns, however, a signal for CAIX could be detected for unknown reason (Figure $6 \mathrm{~F}$ ). 
We have recently shown that CAIX-mediated facilitation of MCT transport activity involves the CAIX proteoglycan-like (PG) domain, which could function as proton antenna for the protein complex [30]. To investigate whether the PG domain might also play a role in the binding of CAIX to CD147, the CAIX mutant CAIX- $\triangle P G$, missing the PG domain, was pulled down with GST-rCD147 (Figure $6 \mathrm{~F}$, white bar). However, pulldown of CAIX- $\triangle P$ G resulted in a similar signal for CAIX as observed for CAIX-WT, indicating that the PG domain is not involved in the binding of CAIX to CD147.

Transport of lactate in cancer cells is primarily mediated by MCT1 and MCT4. However, some cancer cells, including breast carcinoma, colon adenocarcinoma, nonsmall cell lung cancer, ovarian adenocarcinoma and prostate cancer, do also express MCT2 [11,], the chaperon of which is GP70 [18]. The Ig1 domain of GP70 carries a putative CAIX binding site (GP70-Asp95, GP70-Arg130) that is analogue to the binding site in CD147 (Figure $7 \mathrm{~A}$ ). Both residues are conserved in the rat and human isoforms of GP70. To investigate whether CAIX facilitates transport activity of MCT2 and whether this facilitation requires direct binding of CAIX to the transporter's chaperon GP70, we coexpressed rat MCT2 (rMCT2) together with rat GP70-WT (rGP70-WT) or a mutant of the protein and CAIX in Xenopus oocytes (Figure 7 B). Coexpression of rMCT2 and rGP70-WT with CAIX resulted in a significant increase in MCT2 transport activity, both in the direction of influx and efflux (Figure $7 \mathrm{C}$, D). Mutation of rGP70-Arg130 resulted in a loss of functional interaction between MCT2 and CAIX, while mutation of rGP70-Asp95 had no effect on CAIX-mediated facilitation in MCT2 activity (Figure 7 B, C, D). Neither mutation of rGP70-Arg130 nor rGP70-Asp95 had an effect on MCT2 transport activity in the absence of CAIX (Figure $7 \mathrm{C}, \mathrm{D}$ ). Expression of CAIX was confirmed by a $\mathrm{CO}_{2}$ pulse at the end of each experiment (Figure 7 A). Pulldown of CAIX with a GST-fusion protein of rGP70-WT resulted in a robust signal for CAIX, indicating direct binding between the two proteins (Figure $7 \mathrm{E}, \mathrm{F}$ ). Mutation of rGP70-Arg130 and CAIX-His200, respectively, resulted in a loss of interaction, while mutation of rGP70-Asp95 had no significant effect on binding (Figure $7 \mathrm{E}, \mathrm{F}$ ). These results indicate that CAIX could also form a transport metabolon with MCT2/GP70 to facilitate lactate flux in MCT2expressing cancer cells.

\section{Functional interaction between MCT and CAIX can be disrupted by an antibody against CD147}

Inhibition of lactate efflux, either by direct inhibition of $\mathrm{MCT}$ transport activity $[29,52,53]$ or knockdown of CAIX [29], was shown to significantly decrease breast cancer cell proliferation. Since expression of CAIX is predominately associated with cancer cells, the MCT1/4-CD147-CAIX transport metabolon appears as a promising target to interfere with proton/lactate transport in cancer cells. Therefore, we investigated whether the CAIX-mediated increase in MCT transport activity could be abolished by an interfering agent which disrupts binding of CAIX to the transporter's chaperon. The displacement of carbonic anhydrase from the transporter has been termed "metabolon disruption" [54]. As "metabolon disruptor" we choose an antibody which binds to an epitope in the Ig1 domain of CD147, which is situated close to the CAIX binding site at position 73 (Figure 8 A). Preincubation with $1 \mu \mathrm{g} / \mathrm{ml}$ Anti-CD147 fully abolished the CAIX-mediated increase in MCT4 transport activity of MCT4+rCD147+CAIX-coexpressing Xenopus oocytes (Figure 8 B, C). Binding of Anti-CD147 to CD147 did neither influence MCT4 transport activity in the absence of CAIX (Figure 7 C) nor decrease CAIX catalytic activity (Figure 8 D). Furthermore, incubation of oocytes with Anti-CD147 induced no changes in the expression levels of MCT4, CAIX, and CD147 (Figure 9). Interestingly, Anti-CD147 recognized CD147 also in native oocytes (Figure $9 \mathrm{E}, \mathrm{F}$ ). Since Xenopus oocytes endogenously express an analogue of CD147 [55] it appears plausible that the signal for CD147 in native oocytes derived from endogenous Xenopus CD147. 
In addition to the experiments in Xenopus oocytes, incubation with $10 \mu \mathrm{g} / \mathrm{ml}$ of Anti-CD147 resulted in a significant decrease in lactate transport capacity in hypoxic MDA-MB-231 and MCF-7 breast cancer cells, as measured by the rate of change in intracellular lactate concentration, using a lactatesensitive FRET nanosensor (Figure 10). In MDA-MB-231 cells, Anti-CD147 decreased lactate flux by around $60 \%$ (Figure $10 \mathrm{C}$ ). In MCF-7 cells lactate flux was decreased by almost $65 \%$ (Figure $10 \mathrm{~F}$ ). In both cases, disruption of the MCT-CAIX metabolon did not fully abolish MCT transport activity, since direct inhibition of MCT1/4 transport activity in MDA-MB-231 wells with $\alpha$-cyano-4-hydroxycinnamic acid (CHC) and MCT1 transport activity in MCF-7 cells with AR-C155858 (AR-C) resulted in a significant reduction in lactate flux, as compared to preincubation with Anti-CD147 (Figure $10 \mathrm{C}, \mathrm{F}$ ). To investigate the impact of the Anti-CD147-induced metabolon disruption on cancer cell metabolism, we measured acid production in hypoxic MDA-MB-231 and MCF-7 cells in the presence of Anti-CD147 or the MCT inhibitors $\mathrm{CHC}$ and AR-C by determining the change in extracellular $\mathrm{pH}$ using a multi-well cell culture plate with integrated $\mathrm{pH}$ sensor (Figure $11 \mathrm{~A}-\mathrm{D}$ ). Application of AntiCD147 decreased the rate of extracellular acidification by $40 \%$ in MDA-MB-231 cells and $30 \%$ in MCF7 cells, while full inhibition of MCT transport activity with CHC (application of which resulted in a substantial acidification of the cell culture medium) or AR-C resulted in a reduction of acidification by around $80 \%$ (Figure $11 \mathrm{~A}-\mathrm{D}$ ). In line with these results, Anti-CD147 reduced lactate production, as determined by measuring lactate concentration in the culture medium after $24 \mathrm{~h}$, by $48 \%$ in MDAMB-231 and 38\% in MCF-7 cells (Figure $11 \mathrm{E}, \mathrm{F}$ ). Full inhibition of MCT transport activity with $\mathrm{CHC}$ and AR-C, reduced lactate production by $76 \%$ and $53 \%$, respectively (Figure $11 \mathrm{E}, \mathrm{F}$ ).

To investigate whether metabolon disruption with Anti-CD147 has an impact on cancer cell proliferation we determined the number of hypoxic MDA-MB-231 and MCF-7 cells for up to three days in the presence of $10 \mu \mathrm{g} / \mathrm{ml}$ of Anti-CD147 or CHC and AR-C (Figure 12). Anti-CD147 reduced proliferation of hypoxic MDA-MB-231 and MCF-7 cells by $62 \%-94 \%$ and $67 \%-85 \%$, respectively (Figure $12 \mathrm{C}, \mathrm{D}$ ). Inhibition of MCT1 transport activity with AR-C decreased proliferation of MCF-7 cells by $82 \%-88 \%$, while CHC almost fully abolished proliferation of MDA-MB-231 cells (Figure $12 \mathrm{C}$, D). Application of Anti-CD147 at a concentration of only $5 \mu \mathrm{g} / \mathrm{ml}$ resulted in a lower reduction in proliferation of MDA-MB-231 (22\%-50\%) and MCF-7 cells (45\%-68\%) (Figure 13).

Taken together, these results demonstrate that disruption of the MCT1/4-CD147-CAIX transport metabolon with an antibody against the Ig1 domain of CD147 can significantly decrease lactate transport over the cell membrane, which results in a decrease of lactate and proton production (synonymic with a decrease in glycolytic activity) and therefore a decrease in cancer cell proliferation.

\section{Discussion}

The present study shows for the first time that carbonic anhydrase IX forms a transport metabolon with the two major $\mathrm{H}^{+}$/lactate extruders MCT1 and MCT4 in human tumor tissue, but not in healthy breast tissue. The number of transport metabolons increased with higher tumor grade, with the number of MCT1-CAIX metabolons increasing from grade I to grade II and the number of MCT4-CAIX metabolons increasing from grade II to grade III. In line with this, others have shown that CAIX is expressed in breast tumors, but absent in healthy breast tissue [56]. Furthermore, expression of CAIX, MCT1, and MCT4 have all been shown to positively correlate with tumor grade and poor prognosis $[2,10,12-14,34-40]$.

It was recently demonstrated by sequential PET/CT and MRI that glycolytic activity increases with higher tumor grade in breast cancer patients [57]. These results are in agreeance with our findings 
that the number of MCT1/4-CAIX transport metabolons increases with higher tumor grade in breast tumor tissue samples. Since a higher glycolytic rate results in increased production of lactate and protons, these cells would also require a higher $\mathrm{H}^{+} /$lactate efflux capacity, which could be met by an increased amount of MCT1/4-CAIX transport metabolons in the cell membrane. Interestingly, the ratio between MCT1-CAIX and MCT4-CAIX metabolons seems to change with higher tumor grade. MCT4 displays a lower affinity for lactate than MCT1, but has a higher transport capacity [6-8]. Therefore MCT4, the expression of which was found to be upregulated in cancer cells under hypoxia [58], is considered a high capacity lactate exporter, while MCT1 was suggested to serve both as a lactate importer and exporter in cancer cells, depending on the cell's metabolic profile [59, 60]. It could be speculated that in low grade tumors, which show lower overall glycolytic activity, a glycolytic population of cells, which is situated in the hypoxic regions of the tumor, might function as lactate exporters, while another population of cells takes up lactate for oxidative energy production, as previously hypothesized [59]. In that case moderate lactate export and import could be mediated by MCT1 in cooperation with CAIX. With increasing glycolytic activity, as observed with higher tumor grade, cells would require maximum efflux capacity for lactate and protons, which could only be met by a transport metabolon formed by MCT4 and CAIX.

The necessity for an increasing amount of MCT1/4-CAIX transport metabolons in higher grade tumors could also derive from progressing restriction of acid removal. MRI studies on breast cancer patients demonstrated that the apparent diffusion coefficient (ADC) decreased with higher tumor grade [57, $61,62]$. It can be assumed that a lower diffusion coefficient indicates reduced venting of lactate and protons from the tumor mass. This reduction would result in accumulation of both ions in tumor extracellular space, which, in turn, would create an unfavorable gradient for proton-coupled lactate export. Especially diffusive flux of the highly-buffered protons could be significantly restricted in tumor tissue [63]. In such an environment, efficient proton handling seems crucial for protoncoupled lactate transport across the membrane. We have previously suggested that intracellular and extracellular carbonic anhydrases can function as "proton antennae" for MCTs by mediating the rapid exchange of protons between the transporter pore and the surrounding protonatable residues [29, 64-67]. In CAIX, proton transfer between MCT and surrounding protonatable residues seems to be mediated by acidic residues within the enzyme's proteoglycan-like domain [30]. Rapid $\mathrm{H}^{+}$transfer between protonatable sites can be mediated by electrostatic repulsion caused by overlapping Coulomb cages, which would require a maximum distance below $1 \mathrm{~nm}$ between the involved residues [68-70]. Such a close proximity could be achieved by direct binding of the proteins. Previous studies have shown that intracellular CAll binds to a cluster of three glutamic acid residues in the Cterminal tail of $\mathrm{MCT} 1\left(\mathrm{E}^{489} \mathrm{EE}\right)$ and $\mathrm{MCT} 4\left(\mathrm{E}^{431} \mathrm{EE}\right)$, respectively $[71,72]$. Extracellular $\mathrm{CAs}$, however, do not directly interact with the transporter but indirectly via the transporter's chaperons. We recently showed that CAIV, the catalytic domain of which is tethered to the extracellular face of the plasma membrane via a glycosylphosphatidylinositol (GPI) anchor, binds to Glu73 in the Ig1 domain of CD147 [49]. CAIV binding is mediated by His88, which also serves as central residue of the enzyme's intramolecular proton shuttle $[49,73]$. In the present study, we demonstrate that CAIX binds to the Ig1 domain of CD147 (and GP70). CD147 binding is mediated by Glu73 (Lys73 in rat CD147 and Arg130 in rat/human GP70), while in CAIX binding requires His200. Molecular docking shows that CD147-Glu73 can form a hydrogen bond with CAIX-His200 in the "in" confirmation, with a distance of $2.1 \AA$ between the two binding partners (Figure $14 \mathrm{~A}$ ). Binding of the chaperon to CAIX-His200 is mediated either by an acidic residue (hCD147-Glu73), which serves as proton acceptor in a hydrogen bond, or an alkaline residue (rCD147-Lys73 or r/hGP70-Arg130), which serves as proton acceptor. Therefore CAIX-His200 must either serve as proton donor or proton acceptor, depending on its 
binding partner. We could previously show that CAIV-His88 (the homologue to CAIX-His200) which binds to the Ig1 domain of CD147 and GP70, can indeed either serve as hydrogen donor or hydrogen acceptor, depending on whether it binds to hCD147-Glu73 or to rCD147-Lys73 / hGP70-Arg130 [49]. Therefore, it can be assumed that CAIX-His200 also forms a hydrogen bond with hCD147-Glu73 or rCD147-Lys73 / hGP70-Arg130. This binding would bring CAIX close enough to the transport pore to establish an efficient proton shuttle between transporter and enzyme. Indeed, mutation of either rCD147-Lys73 or CAIX-His200 does not only result in a loss of binding between CD147 and CAIX, but also in a loss of functional interaction between MCT1/4 and CAIX (for CAIX-His200, see Figure 4 in [29]). Interestingly, CAIX-His200, which serves as binding site for CD147/GP70, does also represent the central residue of the enzyme's intramolecular proton shuttle. We recently showed for intracellular CAll, that CAII-His64 (the central residue of the enzyme's intramolecular $\mathrm{H}^{+}$shuttle), mediates binding of the enzyme to an acidic cluster in the MCT1/4 C-terminal tail, but is not involved in the transfer of protons between transporter and enzyme [66]. This proton transfer is instead mediated by the two acidic residues CAll-Glu69 and CAll-Asp72 at the protein surface [66]. The catalytic domain of CAIX does not seem to feature a homologue cluster to CAll-Glu69 and CAII-Asp72, however, the proteoglycan-like domain of CAIX features 18 glutamate and 8 aspartate residues, which have been suggested to function as an intramolecular proton buffer [74]. Truncation of the PG domain resulted in a loss of functional interaction between MCT1/4 and CAIX [30] even though in this study, binding of CAIX to CD147 persisted after truncation. Taken together, the data indicate that CAIX, which binds to the Ig1 domain of the MCT chaperon CD147 (or GP70) via CAIX-His200, facilitates the acidic residues in its $P G$ domain to rapidly exchange protons between transporter pore and the surrounding protonatable residues (Figure $14 \mathrm{~B}_{1}$ ). This rapid $\mathrm{H}^{+}$-exchange would counteract the formation of proton-microdomains (local accumulation or depletion of protons) at the extracellular site of the transporter pore and could thereby drive proton-coupled lactate flux across the cell membrane.

Inhibition of CAIX catalytic activity has been widely considered as a potential therapeutic strategy for hypoxic tumors [75]. However, most of the inhibitors tested so far bind to a moiety apart from the His200 and might therefore not target the direct and functional interaction between MCT1/4-CD147 and CAIX [76]. To test whether disruption of the MCT-CD147-CAIX transport metabolon could impact on cancer cell metabolism and decrease cell proliferation we used an antibody against CD147 (AntiCD147), which targets a moiety close to the CD147-Glu73. Application of Anti-CD147 resulted in the total loss of CAIX-induced increase in MCT4 transport activity in Xenopus oocytes, indicating that the antibody does indeed disrupt the interaction between MCT1-CD147 and CAIX. In MCF-7 and MDAMB-231 cancer cells, disruption of the transport metabolon resulted in a significant rate reduction, but no full inhibition of lactate flux. This is not surprising as MCT transport activity is increased by carbonic anhydrases, but MCTs are already active in the absence of the enzyme. However, disruption of the transport metabolon with Anti-CD147 resulted in a significant decrease in lactate and proton production and ultimately a decrease in cell proliferation. These results indicate that disruption of the transport metabolon results in a decrease of MCT transport activity, which leads to intracellular lactate accumulation and inhibition of glycolytic activity, which in turn results in decreased cell proliferation (Figure $14 \mathrm{~B}_{2}$ ).

Direct inhibition of MCT transport activity by small molecule inhibitors like AR-C155858 or AZD3965 is considered a therapeutic strategy for tumor treatment $[52,53,77]$. Since metabolon disruption only reduces, not fully abolishes MCT transport activity, direct inhibition of MCT1 and MCT4 seems more efficient for cancer treatment on the cellular level. However, MCTs are ubiquitously expressed in the human body and play a central function in the energy metabolism of a wide range of tissues, 
including heart and skeletal muscle, liver and brain [77-80]. Therefore, systemic application of a high dose of MCT inhibitors, which would be required for full inhibition of MCT transport activity in a tumor, could be expected to produce severe side effects in other tissues. Therefore, systemic administration of a MCT inhibitor could also only aim on reduction, but not full inhibition of MCT transport activity within the tumor. CAIX, however, is expressed in few healthy tissues, including stomach and gallbladder, but highly upregulated in many solid tumors [32]. Therefore, targeted disruption of the MCT-CD147-CAIX transport metabolon should cause fewer side effects in other tissue than direct targeting of MCT transport function. However, such targeted inhibition has to be directed against CAIX, which is the only part of the MCT-CD147-CAIX metabolon that is exclusively expressed in cancer cells. We therefore suggest a screen for small molecule inhibitors or antibodies against CAIX, which could interfere with binding of the enzyme to the Ig1 domain of CD147, to selectively reduce lactate transport capacity in cancer cells, without interfering with lactate flux in healthy tissue.

Taken together the results provide a proof of concept that the MCT1/4-CD147-CAIX transport metabolon, found in breast cancer tissue, can be exploited as a potential drug target to interfere with cancer cell's energy metabolism in order to reduce cell proliferation and thereby tumor progression.

\section{Materials and Methods}

\section{Tissue micro array}

Human breast tissue micro arrays were purchased from Novus Biological (NBP2-47174). The microarrays contain 16 cases of breast cancer, each in duplicates, with corresponding uninvolved tissue from the same patient as control (48 cores, $2 \mathrm{~mm}$ in diameter, $4 \mu \mathrm{m}$ thick). According to the manufacturer, all tissues were from surgical resection, fixed in $10 \%$ neutral buffered formalin for 24 hours and processed using identical standard operating procedures. The specifications of the tumor samples are given in Table 1.

\section{Cultivation of breast cancer cell lines}

The human breast adenocarcinoma cell lines MCF-7 (DSMZ-No. ACC-115) and MDA-MB-231 (DSMZNo. ACC-732) were purchased from the German Collection of Microorganisms and Cell Cultures (DSMZ, Braunschweig, Germany). If not mentioned otherwise, both cell lines were cultured in RPMI1640 medium with L-glutamine and sodium bicarbonate (R8758, Sigma-Aldrich, Germany), supplemented with $10 \%$ fetal bovine serum (F7524, Sigma-Aldrich), and 1\% penicillin-streptomycin (P4333, Sigma-Aldrich). Cells were either incubated under normoxia (95\% air, 5\% $\mathrm{CO}_{2}$ ) or under hypoxia $\left(94 \% \mathrm{~N}_{2}, 5 \% \mathrm{CO}_{2}, 1 \% \mathrm{O}_{2}\right)$ in humidified cell culture incubators. Both cell lines were subcultivated for a maximum of 15 passages and tested negative for contamination with mycoplasma.

\section{Interfering antibodies and inhibitors}

Mouse monoclonal Anti-CD147 $\operatorname{lgG}_{1}$, directed against amino acids 13-51 within the Ig1 domain of human CD147 was purchased from Santa Cruz Biotechnology (sc-374101). Before the antibody was used in cell culture or on Xenopus oocytes, $\mathrm{NaN}_{3}$ was removed by exchanging the buffer solution for sterile PBS, using a protein concentrator centrifuge column with a molecular cut-off of $10 \mathrm{kDa}$ (Pierce $^{\mathrm{TM}}$ Protein Concentrator PES, 10K MWCO, 2-6 ml; No. 88516). Xenopus oocytes (kept in saline 
without serum) were incubated with $1 \mu \mathrm{g} / \mathrm{ml}$ of Anti-CD147 in oocyte saline for 24 hours. If not mentioned otherwise, MCF-7 and MDA-MB-231 cells were incubated with $10 \mu \mathrm{g} / \mathrm{ml}$ of Anti-CD147, to account for unspecific binding of the antibodies to compounds in the culture medium. Cells were incubated for 24 hours to ensure maximum binding of the antibodies. The MCT1 inhibitor AR-C15585 was purchased from Tocris Bioscience (No. 4960). The inhibitor was dissolved at a concentration of $10 \mathrm{mM}$ in dimethyl sulfoxide (DMSO) and filtered sterile. AR-C155858 was used at a working contraction of $300 \mathrm{nM}$. The generic MCT inhibitor $\alpha$-cyano-4-hydroxycinnamic acid (CHC) was purchased from Sigma-Aldrich (No. 476870). CHC was dissolved in DMSO at a concentration of $1 \mathrm{M}$ and filtered sterile. The inhibitor was used at a working concentration of $5 \mathrm{mM}$.

\section{In situ proximity ligation assay}

Interaction between MCT1, MCT4 and CAIX in human breast cancer tissue micro arrays, as well as in cultivated MCF-7 and MDA-MB-231 cells, was examined using the Duolink ${ }^{\circledast}$ in situ Proximity Ligation Assay (PLA) Kit (DUO92103, Sigma-Aldrich). The protocol for the PLA in cultivated breast cancer cells has been described in detail previously (Noor et al., 2018). MCF-7 cells where cultured in RPMI medium as described above. MDA-MB-231 cells were cultured in Leibovitz-L15 medium (No. 11415; ThermoFisher), supplemented with $10 \%$ fetal calf serum (F413, Sigma-Aldrich), $1 \%$ penicillin/streptomycin (15149, Thermo Fisher), and 5 mM D-glucose (16325, Sigma-Aldrich). The PLA was carried out with the following antibodies: goat anti-MCT1 polyclonal antibody (T-19), sc-14917, Santa Cruz Biotechnology, $1 \mathrm{\mu g} / \mathrm{ml}$; goat anti-MCT4 polyclonal antibody (C-17), sc-14930, Santa Cruz Biotechnology, $1 \mu \mathrm{g} / \mathrm{ml}$; mouse anti-CAIX monoclonal antibody (M75), kindly provided by Dr. Silvia Pastorekova [81], $1 \mu \mathrm{g} / \mathrm{ml}$. For better visualization of cells, actin filaments were stained with Alexa Fluor 488-labelled phalloidin (1:500; A12379; Life Technologies). Nuclei were stained with 4',6diamidino-2-phenylindole (DAPI), added to the mounting medium (DU082040, Sigma-Aldrich). Pictures were taken with a Zeiss LSM700 confocal laser scanning microscope, using a 40x oil immersion objective (EC Plan-Neofluar 40x/1.3; Carl Zeiss AG). For each sample, seven pictures were taken at random locations.

For dewaxing of the tissue micro array prior to staining, the slides were backed for $30 \mathrm{~min}$ at $60^{\circ} \mathrm{C}$ and washed three times with xylene. The procedure was repeated until samples showed a white color without any inclusions. Afterwards, slides were rehydrated by incremental 10 min incubation with decreasing alcohol concentration $(100 \%, 90 \%, 70 \%, 50 \% \mathrm{EtOH})$. The tissue was incubated in deionized $\mathrm{H}_{2} \mathrm{O}$ for 5 min, washed 3 times with phosphate-buffered saline (PBS) and permeabilized in 0.4\% Triton X-100 (T878, Sigma-Aldrich), 1\% donkey serum (D9663, Sigma-Aldrich). The PLA was then carried out the same way as described for cultured cells. Pictures were taken with a Zeiss LSM700 confocal laser scanning microscope, using a $25 \mathrm{x}$ oil immersion objective (LD LCI Plan-Apochromat 25x/0.8 Imm Korr DIC; Carl Zeiss AG). For each tissue sample two pictures were taken at random location. Every breast cancer sample was present in duplicate with one sample of corresponding uninvolved breast tissue. PLA signals were analyzed using the software ImageJ.

\section{Antibody staining in cultured cancer cells}

Conventional antibody staining of cultured breast cancer cells was described in detail previously [29, 66]. The antibodies used for conventional antibody staining were identical to the antibodies used for the PLA and were used in the same concentration. Pictures were taken with a Zeiss LSM700 confocal laser scanning microscope, using a 40x oil immersion objective (EC Plan-Neofluar 40x/1.3; Carl Zeiss $A G)$. 


\section{Western Blot analysis}

Protein quantification in Xenopus oocytes by western blot analysis was described in detail previously [82]. In brief, oocytes were lysed in PBS with $1 \%$ ionic detergent and protease inhibitors. Lysate was cleared by centrifugation for $15 \mathrm{~min}$ at $15000 \mathrm{xg}, 4^{\circ} \mathrm{C} .25 \mu \mathrm{g}$ of total protein were separated on a $12 \%$ SDS gel and blotted to a polyvinylidene difluoride membrane (Roti-PVDF, pore size $0.45 \mu \mathrm{m}$, CarlRoth $\mathrm{GmbH}$ ). CAIX was labeled with mouse anti-CAIX monoclonal antibody (M75; [81]; $0.4 \mu \mathrm{g} / \mathrm{ml}$ ); MCT4 was labeled with rabbit Anti-MCT4 polyclonal antibody (AB3314P, Millipore; $4 \mu \mathrm{g} / \mathrm{ml}$ ); CD147 was labeled with mouse Anti-CD147 monoclonal antibody (sc-374101, Santa Cruz Biotechnology; 0.1 $\mu \mathrm{g} / \mathrm{ml}$ ); $\beta$-tubulin was labeled with mouse Anti- $\beta$-tubulin monoclonal antibody (T5201, Sigma-Aldrich; $2 \mu \mathrm{g} / \mathrm{ml}$ ). Quantification of the bands was carried out using the software ImageJ. Concentrations of CAIX, MCT4, and CD147, respectively, were normalized to the concentration of $\beta$-tubulin in the same sample.

\section{Pull-down of CAIX with GST fusion proteins}

CAIX was pulled down with GST fusion proteins of CD147 and GP70, respectively, using the Pierce ${ }^{\mathrm{TM}}$ GST protein interaction pull-down Kit (21516, Thermo Fisher), as previously described [49, 72]. In brief, GST-fusion proteins of the Ig1 domain of human CD147, rat CD147, and rat GP70, respectively, cloned into the expression vector pGEX-2T (GE Healthcare), were expressed in E. coli BL21 cells and coupled to glutathione-coated agarose beads. CAIX was expressed in Xenopus oocytes, as described in the next chapter. For each pulldown, lysate from 30 oocytes was added to the beads. The pulldown was then analyzed using western blot. CAIX was labelled with mouse anti-CAIX monoclonal antibody (M75; [81]; $0.4 \mu \mathrm{g} / \mathrm{ml}$ ); GST was labeled with mouse Anti-GST Tag monoclonal antibody (05782, Merck Chemicals; $2.5 \mu \mathrm{g} / \mathrm{ml}$ ). To account for variations in the amount of fusion protein, each signal for CAIX was normalized to the corresponding signal for GST.

\section{Heterologous protein expression in Xenopus oocytes}

Protein expression in Xenopus oocytes was carried out as previously described [83, 84]. In brief, CDNA coding for human CAIX, rat MCT1, rat MCT2, rat MCT4, rat CD147-WT or a mutant of the protein, as well as rat GP70-WT or mutant, all cloned into the Xenopus expression vector pGEM-HeJuel, was transcribed in vitro using the Invitrogen $^{\mathrm{TM}}$ Ambion $^{\mathrm{TM}}$ mMESSAGE mMACHINE ${ }^{\mathrm{TM}}$ T7 Transcription Kit (Thermo Fisher). Xenopus laevis females were purchased from the Radboud University, Nijmegen, Netherlands. The procedure for surgical removal of oocytes from anaesthetized frogs was approved by the Landesuntersuchungsamt Rheinland-Pfalz, Koblenz (23 17707/A07-2-003 §6) and the Niedersächsisches Landesamt für Verbraucherschutz und Lebensmittelsicherheit, Oldenburg (33.19-42502-05-17A113). Oocytes were singularized by collagenase treatment for $1 \mathrm{~h}$ at $28^{\circ} \mathrm{C}$ in $\mathrm{Ca}^{2+}$-free oocyte saline. Singularized oocytes were stored in $\mathrm{Ca}^{2+}$-containing oocyte saline $\left(82.5 \mathrm{mM} \mathrm{NaCl}, 2.5 \mathrm{mM} \mathrm{KCl}, 1 \mathrm{mM} \mathrm{CaCl}, 1 \mathrm{mM} \mathrm{MgCl}, 1 \mathrm{mM} \mathrm{Na}_{2} \mathrm{HPO}_{4}\right.$, $5 \mathrm{mM}$ HEPES, $\mathrm{pH} 7.8$ ) at $18^{\circ} \mathrm{C}$. Oocytes of the developmental stages IV and $\mathrm{V}$ were injected with $5 \mathrm{ng}$ of cRNA coding for MCT1, MCT2, or MCT4, together with $10 \mathrm{ng}$ of CRNA coding for rCD147-WT or a mutant of rCD147, or rGP70-WT or a mutant of rGP70, and 5 ng of CRNA coding for CAIX-WT.

\section{Measurements of intracellular $\mathrm{H}^{+}$concentrations in Xenopus oocytes}

Determination of intracellular $\mathrm{H}^{+}$concentrations in Xenopus oocytes with ion-sensitive microelectrodes was described in detail previously [84, 85]. Oocytes were clamped to a holding potential of $-40 \mathrm{mV}$ as previously described $[84,85]$. All measurements were carried out in oocyte saline, $\mathrm{pH} 7.0$, in the nominal absence of $\mathrm{CO}_{2} / \mathrm{HCO}_{3}{ }^{-}$, at room temperature. In lactate-containing 
solution, $\mathrm{NaCl}$ was replaced by $\mathrm{Na}$-L-lactate in equimolar amounts. For $\mathrm{CO}_{2} / \mathrm{HCO}_{3}^{-}$-buffered saline, $\mathrm{NaCl}$ was replaced by $\mathrm{NaHCO}_{3}$ and the solution was constantly aerated with $5 \% \mathrm{CO}_{2} / 95 \% \mathrm{O}_{2}$. The rate of change in intracellular $\mathrm{H}^{+}$concentration was analyzed by determining the slope of a linear regression fit using OriginPro 8.6 (OriginLab Corporation). Recording and data analysis has been described in detail previously [84].

\section{Lactate imaging in cancer cells}

Relative changes in intracellular lactate concentration in individual MCF-7 and MDA-MB-231 cells were measured using the lactate-sensitive FRET nanosensor Laconic. The specifications of the sensor have been described previously [86]. Transduction of MCF-7 and MDA-MB-231 cells with Laconic has been described in detail previously $[29,30]$. In short, MCF-7 and MDA-MB-231 cells were plated on glass coverslips in serum-free Gibco OptiMEM medium (Life Technologies) and transduced with $4.8 \times 10^{10} \mathrm{PFU}$ of Ad5-Laconic (Vector Biolabs). After 4h RPMI medium was added and cells were incubated overnight under normoxic conditions. After $24 \mathrm{~h}$ transduction was stopped by medium exchange and cells were incubated for at least three days under hypoxia $\left(\begin{array}{ll}1 \% & \mathrm{O}_{2}\end{array}\right)$. Imaging experiments were performed in HEPES-buffered saline $\left(143 \mathrm{mM} \mathrm{NaCl}, 5 \mathrm{mM} \mathrm{KCl}, 1 \mathrm{mM} \mathrm{MgSO}{ }_{4}, 1\right.$ $\mathrm{mM} \mathrm{Na} 2 \mathrm{HPO}_{4}, 10 \mathrm{mM}$ HEPES, $2 \mathrm{mM} \mathrm{CaCl}, \mathrm{pH} 7.2$ ) in the nominal absence of $\mathrm{CO}_{2} / \mathrm{HCO}_{3}{ }^{-}$at $21^{\circ} \mathrm{C}$. Perfusion rate was set to $2 \mathrm{ml} / \mathrm{min}$. Image acquisition was carried out with a Leica SP2 inverse confocal laser scanning microscope (Leica Microsystems IR $\mathrm{GmbH}$ ), equipped with a 20x dry objective (HC PL APO 20x/0.70 CS). Laconic was excited at $458 \mathrm{nM}$ and the emission light split into a 460-500 $\mathrm{nm}$ (mTFP) and a 520-550 nm (Venus) fraction. Pictures were taken at a sampling rate of $0.2 \mathrm{~Hz}$. For ratiometric imaging of lactate concentration, the $460-500 \mathrm{~nm}$ fraction was divided by the 520-550 $\mathrm{nm}$ fraction. Data analysis was carried out with ImageJ and OriginPro 8.6.

\section{Determination of proton and lactate production in cancer cells}

Extracellular $\mathrm{pH}$ values of cultured cells were monitored using a SDR SensorDish ${ }^{\circledR}$ Reader (PreSens Precision Sensing GmbH). MDA-MB-231 and MCF-7 cells, respectively were plated in a 24-well HydroDish $^{\circledR}$ HD24 cell culture dish at a density of $10^{5}$ cells/well. Every well of the HydroDish ${ }^{\circledR}$ is equipped with a $\mathrm{pH}$ sensor to allow online monitoring of extracellular $\mathrm{pH}$ during incubation. Cells were grown for three days under hypoxic conditions. Afterwards culture medium was exchanged by $600 \mu \mathrm{l}$ of new medium, containing interfering antibody or inhibitors. Cells were incubated for $24 \mathrm{~h}$ and $\mathrm{pH}$ values were recorded every 5 minutes. After the $24 \mathrm{~h}$ incubation $500 \mathrm{ml}$ of the medium were removed from the culture plate and deproteinized using perchloric acid and $\mathrm{KOH}$ precipitation. Lactate concentrations were then determined using an enzymatic assay (L-Lactic Acid (L-Lactate) Assay Kit, Megazyme u.c.). Lactate concentrations were normalized to cell number in each individual well. Therefore the cells were fixed with 4\% PFA in the HydroDish ${ }^{\circledR}$ and nuclei stained with $10 \mu \mathrm{M}$ Hoechst 33342 (H1399; Thermo Fisher) in PBS. For each well, five pictures were taken at random locations and the number of cells was automatically counted using the software ImageJ as described previously [66].

\section{Determination of cell proliferation}

Proliferation of MCF-7 and MDA-MB-231 cells was determined by counting of stained nuclei as previously described (Noor et al., 2018). In brief, cells were plated in 24-well plates at a concentration of $10^{4}$ cells $/ \mathrm{ml}$ in RPMI medium, supplemented with antibodies or inhibitors. After 0 , 1,2 , and 3 days of incubation cells were fixed with 4\% PFA in PBS and nuclei stained with $10 \mu \mathrm{M}$ Hoechst 33342 (H1399; Thermo Fisher). For each well, five pictures were taken at random locations 
and the number of cells was automatically counted using the software ImageJ as described previously [66].

\section{Molecular docking of CD147 and CAIX}

CD147 and CAIX were docked and modeled as described previously [49, 72]. Docking of the two proteins was performed manually using the interactive graphical program COOT to maximize interface interactions followed by energy minimization at the complex interface using Crystallography and NMR System program (CNS) $[87,88]$. The PDBs used to generate the model were $3 \mathrm{~B} 5 \mathrm{H}$ for hCD147 [89] and 4ZAO for CAIX [90]. Complexes were further analyzed and figures were generated using the graphics software Pymol (Schrödinger LLC).

\section{Calculation and statistics}

Statistical values are presented as means \pm standard error of the mean. For calculation of significance in difference one way analysis of variance (ANOVA) was carried out, followed by means comparison using either Scheffé or Bonferroni test, depending on whether datasets show homogeneity of variance or not. Homogeneity of variance was assessed using Levene's test. All tests were carried out using OriginPro 8.6. In the figures shown, a significance level of $p \leq 0.05$ is marked with *, $p \leq 0.01$ with ** and $p \leq 0.001$ with ***.

\section{Acknowledgements}

We thank Heike Kanapin, Sandra Pfeiffer, Hans-Peter Schneider and Patrick Pattar for excellent technical assistance. The work was funded by the Deutsche Forschungsgemeinschaft (to H.M.B.; BE 4310/6-1), the Research Initiative BioComp (to H.M.B), and by stipends from the Lotto-Stiftung Rheinland-Pfalz and the FAZIT Stiftung (to S.A.). 


\section{References}

1. Bray, F., Ferlay, J., Soerjomataram, I., Siegel, R. L., Torre, L. A., and Jemal, A. (2018) Global cancer statistics 2018: GLOBOCAN estimates of incidence and mortality worldwide for 36 cancers in 185 countries. CA. Cancer J. Clin. 68, 394-424

2. Johnson, J. M., Cotzia, P., Fratamico, R., Mikkilineni, L., Chen, J., Colombo, D., Mollaee, M., Whitaker-Menezes, D., Domingo-Vidal, M., Lin, Z., Zhan, T., Tuluc, M., Palazzo, J., Birbe, R. C., and Martinez-Outschoorn, U. E. (2017) MCT1 in Invasive Ductal Carcinoma: Monocarboxylate Metabolism and Aggressive Breast Cancer. Front. cell Dev. Biol. 5, 27

3. Warburg, O., and Minami, S. (1923) Versuche an Überlebendem Carcinom-gewebe. Klin. Wochenschr. 2, 776-777

4. Warburg, O., Wind, F., and Negelein, E. (1927) The metabolism of tumors in the body. J. Gen. Physiol. 8, 519-30

5. Hanahan, D., and Weinberg, R. A. (2011) Hallmarks of cancer: The next generation. Cell. 144, 646674

6. Bröer, S., Rahman, B., Pellegri, G., Pellerin, L., Martin, J. L., Verleysdonk, S., Hamprecht, B., and Magistretti, P. J. (1997) Comparison of lactate transport in astroglial cells and monocarboxylate transporter 1 (MCT 1) expressing Xenopus laevis oocytes. Expression of two different monocarboxylate transporters in astroglial cells and neurons. J. Biol. Chem. 272, 30096-102

7. Bröer, S., Schneider, H. P., Bröer, A., Rahman, B., Hamprecht, B., and Deitmer, J. W. (1998) Characterization of the monocarboxylate transporter 1 expressed in Xenopus laevis oocytes by changes in cytosolic pH. Biochem. J. 333, 167-74

8. Dimmer, K. S., Friedrich, B., Lang, F., Deitmer, J. W., and Bröer, S. (2000) The low-affinity monocarboxylate transporter MCT4 is adapted to the export of lactate in highly glycolytic cells. Biochem. J. 350, 219-27

9. Halestrap, A. P., and Price, N. T. (1999) The proton-linked monocarboxylate transporter (MCT) family: structure, function and regulation. Biochem. J. 343 Pt 2, 281-99

10. Pinheiro, C., Albergaria, A., Paredes, J., Sousa, B., Dufloth, R., Vieira, D., Schmitt, F., and Baltazar, F. (2010a) Monocarboxylate transporter 1 is up-regulated in basal-like breast carcinoma. Histopathology. 56, 860-7

11. Pinheiro, C., Reis, R. M., Ricardo, S., Longatto-Filho, A., Schmitt, F., and Baltazar, F. (2010) Expression of monocarboxylate transporters 1, 2, and 4 in human tumours and their association with CD147 and CD44. J. Biomed. Biotechnol. 2010, 427694

12. Choi, J., Kim, D. H., Jung, W. H., and Koo, J. S. (2013) Metabolic interaction between cancer cells and stromal cells according to breast cancer molecular subtype. Breast Cancer Res. 15, 78

13. Kim, S., Jung, W. H., and Koo, J. S. (2013) The Expression of Glut-1, CAIX, and MCT4 in Mucinous Carcinoma. J. Breast Cancer. 16, 146

14. Kwon, J. E., Jung, W.-H., and Koo, J. S. (2013) The expression of metabolism-related proteins in phyllodes tumors. Tumor Biol. 34, 115-124

15. Luz, M., Perez, M., Azzalis, L., Sousa, L., Adami, F., Fonseca, F., and Alves, B. (2017) Evaluation of MCT1, MCT4 and CD147 Genes in Peripheral Blood Cells of Breast Cancer Patients and Their Potential Use as Diagnostic and Prognostic Markers. Int. J. Mol. Sci. 18, 170

16. Morais-Santos, F., Granja, S., Miranda-Gonçalves, V., Moreira, A. H. J., Queirós, S., Vilaça, J. L., Schmitt, F. C., Longatto-Filho, A., Paredes, J., Baltazar, F., and Pinheiro, C. (2015) Targeting lactate transport suppresses in vivo breast tumour growth. Oncotarget 6, 19177-89 
17. Wilson, M. C., Meredith, D., and Halestrap, A. P. (2002) Fluorescence resonance energy transfer studies on the interaction between the lactate transporter MCT1 and CD147 provide information on the topology and stoichiometry of the complex in situ. J. Biol. Chem. 277, 3666-72

18. Wilson, M. C., Meredith, D., Manning Fox, J. E., Manoharan, C., Davies, A. J., and Halestrap, A. P. (2005) Basigin (CD147) is the target for organomercurial inhibition of monocarboxylate transporter isoforms 1 and 4: The ancillary protein for the insensitive MCT2 is embigin (gp70). J. Biol. Chem. 280, 27213-27221

19. Manoharan, C., Wilson, M. C., Sessions, R. B., and Halestrap, A. P. (2006) The role of charged residues in the transmembrane helices of monocarboxylate transporter 1 and its ancillary protein basigin in determining plasma membrane expression and catalytic activity. Mol. Membr. Biol. 23, 486-98

20. Fossum, S., Mallett, S., and Neil Barclay, A. (1991) The MRC OX-47 antigen is a member of the immunoglobulin superfamily with an unusual transmembrane sequence. Eur. J. Immunol. 21, 671679

21. Muramatsu, T. (2016) Basigin (CD147), a multifunctional transmembrane glycoprotein with various binding partners. J. Biochem. 159, 481-490

22. Nabeshima, K., Iwasaki, H., Koga, K., Hojo, H., Suzumiya, J., and Kikuchi, M. (2006) Emmprin (basigin/CD147): Matrix metalloproteinase modulator and multifunctional cell recognition molecule that plays a critical role in cancer progression. Pathol. Int. 56, 359-367

23. Liu, M., Tsang, J. Y. S., Lee, M., Ni, Y.-B., Chan, S.-K., Cheung, S.-Y., Hu, J., Hu, H., and Tse, G. M. K. (2018) CD147 expression is associated with poor overall survival in chemotherapy treated triplenegative breast cancer. J. Clin. Pathol. 71, 1007-1014

24. Walter, M., Simanovich, E., Brod, V., Lahat, N., Bitterman, H., and Rahat, M. A. (2016) An epitopespecific novel anti-EMMPRIN polyclonal antibody inhibits tumor progression. Oncoimmunology. 5, 112

25. Kuang, Y. H., Liu, Y. J., Tang, L. L., Wang, S. M., Yan, G. J., and Liao, L. Q. (2018) Plasma soluble cluster of differentiation 147 levels are increased in breast cancer patients and associated with lymph node metastasis and chemoresistance. Hong Kong Med. J. 24, 252-260

26. Swietach, P., Hulikova, A., Vaughan-Jones, R. D., and Harris, A. L. (2010) New insights into the physiological role of carbonic anhydrase IX in tumour pH regulation. Oncogene. 29, 6509-21

27. Parks, S. K., Chiche, J., and Pouysségur, J. (2013) Disrupting proton dynamics and energy metabolism for cancer therapy. Nat. Rev. Cancer. 13, 611-23

28. Pastorek, J., and Pastorekova, S. (2015) Hypoxia-induced carbonic anhydrase IX as a target for cancer therapy: From biology to clinical use. Semin. Cancer Biol. 31, 52-64

29. Jamali, S., Klier, M., Ames, S., Barros, L. F., McKenna, R., Deitmer, J. W., and Becker, H. M. (2015) Hypoxia-induced carbonic anhydrase IX facilitates lactate flux in human breast cancer cells by noncatalytic function. Sci. Rep. 5, 13605

30. Ames, S., Pastorekova, S., and Becker, H. M. (2018) The proteoglycan-like domain of carbonic anhydrase IX mediates non-catalytic facilitation of lactate transport in cancer cells. Oncotarget. 9, 27940-27957

31. Wykoff, C. C., Beasley, N. J., Watson, P. H., Turner, K. J., Pastorek, J., Sibtain, A., Wilson, G. D., Turley, H., Talks, K. L., Maxwell, P. H., Pugh, C. W., Ratcliffe, P. J., and Harris, A. L. (2000) Hypoxiainducible expression of tumor-associated carbonic anhydrases. Cancer Res. 60, 7075-83

32. Pastorekova, S., and Zavada, J. (2004) Carbonic anhydrase IX ( CA IX ) as a potential target for cancer therapy Review Article. Caner Ther. 2, 245-262 
33. Pastorek, J., Pastoreková, S., Callebaut, I., Mornon, J. P., Zelník, V., Opavský, R., Zat'ovicová, M., Liao, S., Portetelle, D., and Stanbridge, E. J. (1994) Cloning and characterization of MN, a human tumor-associated protein with a domain homologous to carbonic anhydrase and a putative helixloop-helix DNA binding segment. Oncogene. 9, 2877-88

34. Pinheiro, C., Sousa, B., Albergaria, A., Paredes, J., Dufloth, R., Vieira, D., Schmitt, F., and Baltazar, F. (2011) GLUT1 and CAIX expression profiles in breast cancer correlate with adverse prognostic factors and MCT1 overexpression. Histol. Histopathol. 26, 1279-86

35. Vermeulen, J. F., van Brussel, A. S. A., van der Groep, P., Morsink, F. H. M., Bult, P., van der Wall, E., and van Diest, P. J. (2012) Immunophenotyping invasive breast cancer: paving the road for molecular imaging. BMC Cancer. 12, 240

36. Choi, J., Jung, W. H., and Koo, J. S. (2012) Metabolism-related proteins are differentially expressed according to the molecular subtype of invasive breast cancer defined by surrogate immunohistochemistry. Pathobiology. 80, 41-52

37. Adams, A., van Brussel, A. S., Vermeulen, J. F., Mali, W. P., van der Wall, E., van Diest, P. J., and Elias, S. G. (2013) The potential of hypoxia markers as target for breast molecular imaging -- a systematic review and meta-analysis of human marker expression., BMC Cancer. 13, 538

38. Currie, M. J., Beardsley, B. E., Harris, G. C., Gunningham, S. P., Dachs, G. U., Dijkstra, B., Morrin, H. R., Wells, J. E., and Robinson, B. A. (2013) Immunohistochemical analysis of cancer stem cell markers in invasive breast carcinoma and associated ductal carcinoma in situ: relationships with markers of tumor hypoxia and microvascularity. Hum. Pathol. 44, 402-11

39. Bane, A. L., Whelan, T. J., Pond, G. R., Parpia, S., Gohla, G., Fyles, A. W., Pignol, J. P., Pritchard, K. I., Chambers, S., and Levine, M. N. (2014) Tumor factors predictive of response to hypofractionated radiotherapy in a randomized trial following breast conserving therapy. Ann. Oncol. 25, 992-998

40. Ozretic, P., Alvir, I., Sarcevic, B., Vujaskovic, Z., Rendic-Miocevic, Z., Roguljic, A., and BeketicOreskovic, L. (2018) Apoptosis regulator Bcl-2 is an independent prognostic marker for worse overall survival in triple-negative breast cancer patients. Int. J. Biol. Markers. 33, 109-115

41. Tan, E. Y., Yan, M., Campo, L., Han, C., Takano, E., Turley, H., Candiloro, I., Pezzella, F., Gatter, K. C., Millar, E. K. A., O'Toole, S. A., McNeil, C. M., Crea, P., Segara, D., Sutherland, R. L., Harris, A. L., and Fox, S. B. (2009) The key hypoxia regulated gene CAIX is upregulated in basal-like breast tumours and is associated with resistance to chemotherapy. Br. J. Cancer. 100, 405-411

42. Beketic-Oreskovic, L., Ozretic, P., Rabbani, Z. N., Jackson, I. L., Sarcevic, B., Levanat, S., Maric, P., Babic, I., and Vujaskovic, Z. (2011) Prognostic significance of carbonic anhydrase IX (CA-IX), endoglin (CD105) and 8-hydroxy-2'-deoxyguanosine (8-OHdG) in breast cancer patients. Pathol. Oncol. Res. 17, 593-603

43. Svastova, E., Witarski, W., Csaderova, L., Kosik, I., Skvarkova, L., Hulikova, A., Zatovicova, M., Barathova, M., Kopacek, J., Pastorek, J., and Pastorekova, S. (2012) Carbonic anhydrase IX interacts with bicarbonate transporters in lamellipodia and increases cell migration via its catalytic domain. $J$. Biol. Chem. 287, 3392-402

44. Johnson, D. E., and Casey, J. R. (2009) Bicarbonate Transport Metabolons. in Drug Design of ZincEnzyme Inhibitors, pp. 415-437, John Wiley \& Sons, Inc., Hoboken, NJ, USA, pp 415-437

45. Moraes, T. F., and Reithmeier, R. A. F. (2012) Membrane transport metabolons. Biochim. Biophys. Acta-Biomembr. 1818, 2687-2706

46. Deitmer, J. W., and Becker, H. M. (2013) Transport metabolons with carbonic anhydrases. Front. Physiol. 4, 291 
47. Becker, H. M., Klier, M., and Deitmer, J. W. (2014) Carbonic anhydrases and their interplay with acid/base-coupled membrane transporters. in Sub-cellular biochemistry (Frost, S. C., and McKenna, R. eds), pp. 105-34, Subcellular Biochemistry, Springer Netherlands, Dordrecht, 75, 105-34

48. Pinheiro, C., Longatto-Filho, A., Azevedo-Silva, J., Casal, M., Schmitt, F. C., and Baltazar, F. (2012) Role of monocarboxylate transporters in human cancers: state of the art. J. Bioenerg. Biomembr. 44, 127-39

49. Forero-Quintero, L. S., Ames, S., Schneider, H.-P., Thyssen, A., Boone, C. D., Andring, J. T., McKenna, R., Casey, J. R., Deitmer, J. W., and Becker, H. M. (2018) Membrane-anchored carbonic anhydrase IV interacts with monocarboxylate transporters via their chaperones CD147 and GP70. J. Biol. Chem. 294, 593-607

50. Pértega-Gomes, N., Vizcaíno, J. R., Gouveia, C., Jerõnimo, C., Henrique, R. M., Lopes, C., and Baltazar, F. (2013) Monocarboxylate transporter 2 (MCT2) as putative biomarker in prostate cancer. Prostate. 73, 763-769

51. Eilertsen, M., Andersen, S., Al-Saad, S., Kiselev, Y., Donnem, T., Stenvold, H., Pettersen, I., AlShibli, K., Richardsen, E., Busund, L. T., and Bremnes, R. M. (2014) Monocarboxylate transporters 1-4 in NSCLC: MCT1 is an independent prognostic marker for survival. PLoS One. 9, e105038

52. Guan, X., Bryniarski, M. A., and Morris, M. E. (2019a) In Vitro and In Vivo Efficacy of the Monocarboxylate Transporter 1 Inhibitor AR-C155858 in the Murine 4T1 Breast Cancer Tumor Model. AAPS J. 21, 3

53. Guan, X., Rodriguez-Cruz, V., and Morris, M. E. (2019b) Cellular Uptake of MCT1 Inhibitors ARC155858 and AZD3965 and Their Effects on MCT-Mediated Transport of L-Lactate in Murine 4T1 Breast Tumor Cancer Cells. AAPS J. 21, 13

54. Alvarez, B. V, Vilas, G. L., and Casey, J. R. (2005) Metabolon disruption: a mechanism that regulates bicarbonate transport. EMBO J. 24, 2499-511

55. Kirk, P., Wilson, M. C., Heddle, C., Brown, M. H., Barclay, A. N., and Halestrap, A. P. (2000) CD147 is tightly associated with lactate transporters MCT1 and MCT4 and facilitates their cell surface expression. EMBO J. 19, 3896-904

56. Chen, C.-L., Chu, J.-S., Su, W.-C., Huang, S.-C., and Lee, W.-Y. (2010) Hypoxia and metabolic phenotypes during breast carcinogenesis: expression of HIF-1alpha, GLUT1, and CAIX. Virchows Arch. 457, 53-61

57. Choi, J. H., Lim, I., Noh, W. C., Kim, H.-A., Seong, M.-K., Jang, S., Seol, H., Moon, H., Byun, B. H., Kim, B. Il, Choi, C. W., and Lim, S. M. (2018) Prediction of tumor differentiation using sequential PET/CT and MRI in patients with breast cancer. Ann. Nucl. Med. 32, 389-397

58. Cheng, C., Edin, N. F. J., Lauritzen, K. H., Aspmodal, I., Christoffersen, S., Jian, L., Rasmussen, L. J., Pettersen, E. O., Xiaoqun, G., and Bergersen, L. H. (2012) Alterations of monocarboxylate transporter densities during hypoxia in brain and breast tumour cells. Cell. Oncol. (Dordr). 35, 217-27

59. Sonveaux, P., Végran, F., Schroeder, T., Wergin, M. C., Verrax, J., Rabbani, Z. N., De Saedeleer, C. J., Kennedy, K. M., Diepart, C., Jordan, B. F., Kelley, M. J., Gallez, B., Wahl, M. L., Feron, O., and Dewhirst, M. W. (2008) Targeting lactate-fueled respiration selectively kills hypoxic tumor cells in mice. J. Clin. Invest. 118, 3930-3942

60. Pisarsky, L., Bill, R., Fagiani, E., Dimeloe, S., Goosen, R. W., Hagmann, J., Hess, C., and Christofori, G. (2016) Targeting Metabolic Symbiosis to Overcome Resistance to Anti-angiogenic Therapy. Cell Rep. 15, 1161-1174

61. Cipolla, V., Santucci, D., Guerrieri, D., Drudi, F. M., Meggiorini, M. L., and De Felice, C. (2014) Correlation between $3 \mathrm{~T}$ apparent diffusion coefficient values and grading of invasive breast carcinoma. Eur. J. Radiol. 83, 2144-2150 
62. Belli, P., Costantini, M., Bufi, E., Giardina, G. G., Rinaldi, P., Franceschini, G., and Bonomo, L. (2015) Diffusion magnetic resonance imaging in breast cancer characterisation: correlations between the apparent diffusion coefficient and major prognostic factors. Radiol. Medica. 120, 268-276

63. Swietach, P. (2019) What is pH regulation, and why do cancer cells need it? Cancer Metastasis Rev. 10.1007/s10555-018-09778-x

64. Becker, H. M., Klier, M., Schüler, C., McKenna, R., and Deitmer, J. W. (2011) Intramolecular proton shuttle supports not only catalytic but also noncatalytic function of carbonic anhydrase II. Proc. Natl. Acad. Sci. U. S. A. 108, 3071-6

65. Noor, S. I., Pouyssegur, J., Deitmer, J. W., and Becker, H. M. (2017) Integration of a 'proton antenna' facilitates transport activity of the monocarboxylate transporter MCT4. FEBS J. 284, 149162

66. Noor, S. I., Jamali, S., Ames, S., Langer, S., Deitmer, J. W., and Becker, H. M. (2018) A surface proton antenna in carbonic anhydrase II supports lactate transport in cancer cells. Elife. 7, 1-31

67. Hiremath, S. A., Surulescu, C., Jamali, S., Ames, S., W Deitmer, J., and M. Becker, H. (2019) Modeling of $\mathrm{pH}$ regulation in tumor cells: Direct interaction between proton-coupled lactate transporters and cancer-associated carbonicanhydrase. Math. Biosci. Eng. 16, 320-337

68. Ädelroth, P., and Brzezinski, P. (2004) Surface-mediated proton-transfer reactions in membranebound proteins. Biochim. Biophys. Acta - Bioenerg. 1655, 102-115

69. Friedman, R., Nachliel, E., and Gutman, M. (2005) Molecular dynamics of a protein surface: ionresidues interactions. Biophys. J. 89, 768-81

70. Gutman, M., Nachliel, E., and Friedman, R. (2006) The dynamics of proton transfer between adjacent sites. Photochem. Photobiol. Sci. 5, 531-7

71. Stridh, M. H., Alt, M. D., Wittmann, S., Heidtmann, H., Aggarwal, M., Riederer, B., Seidler, U., Wennemuth, G., McKenna, R., Deitmer, J. W., and Becker, H. M. (2012) Lactate flux in astrocytes is enhanced by a non-catalytic action of carbonic anhydrase II. J. Physiol. 590, 2333-51

72. Noor, S. I., Dietz, S., Heidtmann, H., Boone, C. D., McKenna, R., Deitmer, J. W., and Becker, H. M. (2015) Analysis of the binding moiety mediating the interaction between monocarboxylate transporters and carbonic anhydrase II. J. Biol. Chem. 290, 4476-4486

73. Hurt, J. D., Tu, C., Laipis, P. J., and Silverman, D. N. (1997) Catalytic properties of murine carbonic anhydrase IV. J. Biol. Chem. 272, 13512-8

74. Innocenti, A., Pastorekova, S., Pastorek, J., Scozzafava, A., De Simone, G., and Supuran, C. T. (2009) The proteoglycan region of the tumor-associated carbonic anhydrase isoform IX acts as anintrinsic buffer optimizing $\mathrm{CO} 2$ hydration at acidic $\mathrm{pH}$ values characteristic of solid tumors. Bioorg. Med. Chem. Lett. 19, 5825-8

75. Supuran, C. T. (2017) Carbonic Anhydrase Inhibition and the Management of Hypoxic Tumors. Metabolites. 7, 48

76. Mboge, M. Y., Chen, Z., Khokhar, D., Wolff, A., Ai, L., Heldermon, C. D., Bozdag, M., Carta, F., Supuran, C. T., Brown, K. D., McKenna, *Robert, Frost, C. J., and Frost, S. C. (2018) A non-catalytic function of carbonic anhydrase IX contributes to the glycolytic phenotype and $\mathrm{pH}$ regulation in human breast cancer cells, 10.1101/505644

77. Halestrap, A. P. (2013) The SLC16 gene family-Structure, role and regulation in health and disease. Mol. Aspects Med. 34, 337-349

78. Bonen, A. (2000) Lactate transporters (MCT proteins) in heart and skeletal muscles. Med. Sci. Sports Exerc. 32, 778-89 
79. Debernardi, R., Pierre, K., Lengacher, S., Magistretti, P. J., and Pellerin, L. (2003) Cell-specific expression pattern of monocarboxylate transporters in astrocytes and neurons observed in different mouse brain cortical cell cultures. J Neurosci Res. 73, 141-155

80. Jackson, V. N., and Halestrap, A. P. (1996) The kinetics, substrate, and inhibitor specificity of the monocarboxylate (lactate) transporter of rat liver cells determined using the fluorescent intracellular pH indicator, 2', 7'-bis(carboxyethyl)-5(6)-carboxyfluorescein. J. Biol. Chem. 271, 861-8

81. Zatovicova, M., Tarábková, K., Svastova, E., Gibadulinová, A., Mucha, V., Jakubícková, L., Biesová, Z., Rafajová, M., Ortova Gut, M., Parkkila, S., Parkkila, A. K., Waheed, A., Sly, W. S., Horak, I., Pastorek, J., and Pastorekova, S. (2003) Monoclonal antibodies generated in carbonic anhydrase IX-deficient mice recognize different domains of tumour-associated hypoxia-induced carbonic anhydrase IX. J. Immunol. Methods. 282, 117-34

82. Klier, M., Schüler, C., Halestrap, A. P., Sly, W. S., Deitmer, J. W., and Becker, H. M. (2011) Transport activity of the high-affinity monocarboxylate transporter MCT2 is enhanced by extracellular carbonic anhydrase IV but not by intracellular carbonic anhydrase II. J. Biol. Chem. 286, 27781-91

83. Becker, H. M., Bröer, S., and Deitmer, J. W. (2004) Facilitated lactate transport by MCT1 when coexpressed with the sodium bicarbonate cotransporter (NBC) in Xenopus oocytes. Biophys. J. 86, 235-47

84. Becker, H. M. (2014) Transport of Lactate: Characterization of the Transporters Involved in Transport at the Plasma Membrane by Heterologous Protein Expression in Xenopus Oocytes. in Neuromethods, pp. 25-43, 90, 25-43

85. Deitmer, J. W. (1991) Electrogenic sodium-dependent bicarbonate secretion by glial cells of the leech central nervous system. J. Gen. Physiol. 98, 637-55

86. San Martín, A., Ceballo, S., Ruminot, I., Lerchundi, R., Frommer, W. B., and Barros, L. F. (2013) A Genetically Encoded FRET Lactate Sensor and Its Use To Detect the Warburg Effect in Single Cancer Cells. PLoS One. 8, e57712

87. Brünger, A. T., Adams, P. D., Clore, G. M., DeLano, W. L., Gros, P., Grosse-Kunstleve, R. W., Jiang, J. S., Kuszewski, J., Nilges, M., Pannu, N. S., Read, R. J., Rice, L. M., Simonson, T., and Warren, G. L. (1998) Crystallography \& NMR system: A new software suite for macromolecular structure determination. Acta Crystallogr. D. Biol. Crystallogr. 54, 905-21

88. Emsley, P., and Cowtan, K. (2004) Coot: Model-building tools for molecular graphics. Acta Crystallogr. Sect. D Biol. Crystallogr. 60, 2126-2132

89. Yu, X. L., Hu, T., Du, J. M., Ding, J. P., Yang, X. M., Zhang, J., Yang, B., Shen, X., Zhang, Z., Zhong, W. De, Wen, N., Jiang, H., Zhu, P., and Chen, Z. N. (2008) Crystal structure of HAb18G/CD147: Implications for immunoglobulin superfamily homophilic adhesion. J. Biol. Chem. 283, 18056-18065

90. Pinard, M. A., Aggarwal, M., Mahon, B. P., Tu, C., and Mckenna, R. (2015) A sucrose-binding site provides a lead towards an isoform-specific inhibitor of the cancer-associated enzyme carbonic anhydrase IX. Acta Crystallogr. Sect. Struct. Biol. Commun. 71, 1352-1358 
Table 1: Specifications of the tissue microarray and number of PLA signals. The tissue micro array was purchased form Novus Biological (Human breast tissue microarray (Tumor), NBP2-47174). The array contains 16 cases of breast cancer (each in duplicates) paired with one sample of adjacent normal tissue. All patients were female. Stage classification: T: Primary Tumor; "T1" Tumor $2 \mathrm{~cm}$ or less in greatest dimension; "T2" Tumor more than $2 \mathrm{~cm}$ but not more than $5 \mathrm{~cm}$ in greatest dimension; "T3" Tumor more than $5 \mathrm{~cm}$ in greatest dimension; "T4" Tumor of any size with direct extension to chest wall or skin. N: Regional Lymph Nodes; "NO" No regional lymph node metastasis; "N1" Metastasis to movable ipsilateral lymph node(s). M: Distant Metastasis; "MO" No distant metastasis. Pathology: "ductal" invasive ductal carcinoma; "tubular" invasive lobular carcinoma; "ductal, lobular" invasive ductal carcinoma, tubular type. Receptor type: "AR" androgen receptor; "ER" estrogen receptor; "PR" progesterone receptor; "HER2" human epidermal growth factor receptor 2 (receptor tyrosine-protein kinase erbB-2, CD340). Staining scoring: "_" no staining; "+" weak staining; "++" moderate staining; "+++" strong staining; "\%" percentage of positive cells. The PLA signals/nucleus derive from two pictures, taken at random locations in each sample. Tumor samples were present in duplicates with one sample of adjacent normal tissue.

\begin{tabular}{|c|c|c|c|c|c|c|c|c|c|c|c|}
\hline Age & Grade & $\begin{array}{l}\text { Stage } \\
\text { (TNM) }\end{array}$ & Pathology & AR & ER & PR & HER2 & $\begin{array}{l}\text { PLA signals/nucleus } \\
\text { MCT1 + CAIX } \\
\text { tumor tissue }\end{array}$ & $\begin{array}{l}\text { PLA signals/nucleus } \\
\text { MCT1 + CAIX } \\
\text { uninvolved tissue }\end{array}$ & $\begin{array}{l}\text { PLA signals/nucleus } \\
\text { MCT4 + CAIX } \\
\text { tumor tissue }\end{array}$ & $\begin{array}{l}\text { PLA signals/nucleus } \\
\text { MCT4 + CAIX } \\
\text { uninvolved tissue }\end{array}$ \\
\hline 28 & 1 & T1NOMO & ductal & - & - & - & +++ & $4.26 \pm 0.60$ & $1.11 \pm 0.14$ & $14.71 \pm 4.57$ & $2.22 \pm 0.26$ \\
\hline 56 & 1 & T1NOMO & ductal & $\begin{array}{c}+ \\
2 \% \\
\end{array}$ & - & - & - & $3.01 \pm 0.69$ & $1.51 \pm 0.22$ & $7.30 \pm 1.96$ & $1.40 \pm 0.69$ \\
\hline 43 & 1 & T4N1M0 & lobular & - & - & $\begin{array}{c}+\sim++ \\
30 \% \\
\end{array}$ & + & $10.50 \pm 3.15$ & $1.84 \pm 0.87$ & $6.05 \pm 1.41$ & $1.02 \pm 0.12$ \\
\hline 47 & $|\sim| \mid$ & T2NOMO & ductal & - & $\begin{array}{c}++ \\
50 \% \\
\end{array}$ & - & $++\sim+++$ & $2.11 \pm 0.60$ & $0.63 \pm 0.0003$ & $4.46 \pm 1.67$ & $1.21 \pm 0.07$ \\
\hline 66 & $|\sim| \mid$ & T2NOMO & $\begin{array}{l}\text { ductal, } \\
\text { tubular }\end{array}$ & - & $\begin{array}{l}+++ \\
90 \% \\
\end{array}$ & - & + & $27.29 \pm 5.24$ & $1.90 \pm 0.99$ & $11.44 \pm 3.20$ & $1.92 \pm 0.35$ \\
\hline 35 & II & T2NOMO & ductal & $\begin{array}{l}++ \\
5 \% \\
\end{array}$ & $\begin{array}{c}++ \\
10 \% \\
\end{array}$ & $\begin{array}{c}++ \\
50 \% \\
\end{array}$ & + & $3.75 \pm 1.49$ & $0.52 \pm 0.07$ & $8.04 \pm 1.53$ & $0.39 \pm 0.23$ \\
\hline 74 & $\|\sim\|$ & T2NOMO & ductal & $\begin{array}{c}+ \\
5 \% \\
\end{array}$ & $\begin{array}{l}+++ \\
90 \%\end{array}$ & $\begin{array}{c}++\sim++++ \\
20 \% \\
\end{array}$ & - & $4.58 \pm 1.72$ & $0.19 \pm 0.02$ & $3.89 \pm 0.58$ & $1.56 \pm 0.65$ \\
\hline 50 & $\|\sim\|$ & T2N1M0 & ductal & $\begin{array}{c}+ \\
5 \% \\
\end{array}$ & $\begin{array}{c}+++_{+++} \\
80 \% \\
\end{array}$ & $\begin{array}{l}+++ \\
90 \%\end{array}$ & + & $3.28 \pm 1.11$ & $0.88 \pm 0.52$ & $6.26 \pm 0.36$ & $1.54 \pm 0.83$ \\
\hline 53 & $\|\sim\|$ & $\mathrm{T} 2 \mathrm{~N} 1 \mathrm{M} 0$ & ductal & $\begin{array}{c}++ \\
50 \% \\
\end{array}$ & - & - & +++ & $17.29 \pm 4,21$ & $2.69 \pm 1.28$ & $33.85 \pm 3.94$ & $2.74 \pm 0.66$ \\
\hline 47 & $\|\sim\|$ & T2NOMO & ductal & - & - & - & +++ & $7.78 \pm 2.86$ & $0.87 \pm 0.01$ & $8.29 \pm 2.01$ & $1.23 \pm 0.03$ \\
\hline 36 & $\|\sim\|$ & T2NOMO & ductal & $\begin{array}{c}++ \\
10 \% \\
\end{array}$ & $\begin{array}{c}++ \\
20 \% \\
\end{array}$ & $\begin{array}{c}++\sim+++ \\
20 \% \\
\end{array}$ & +++ & $4.14 \pm 1.43$ & $0.96 \pm 0.13$ & $3.54 \pm 0.57$ & $1.65 \pm 0.53$ \\
\hline 38 & III & T4NOMO & ductal & - & - & - & - & $16.67 \pm 7.39$ & $0.72 \pm 0.13$ & $30.20 \pm 10.04$ & $0.97 \pm 0.01$ \\
\hline 33 & III & T2NOMO & ductal & \begin{tabular}{c|}
$\begin{array}{c}\text { No tumor } \\
\text { cell }\end{array}$ \\
\end{tabular} & $\begin{array}{c}\text { No tumor } \\
\text { cell }\end{array}$ & - & - & $12.80 \pm 5.13$ & $0.25 \pm 0.17$ & $38.93 \pm 8.63$ & $2.62 \pm 1.47$ \\
\hline 53 & III & T3NOMO & ductal & - & $\begin{array}{l}+++ \\
90 \% \\
\end{array}$ & $\begin{array}{c}++ \\
60 \% \\
\end{array}$ & $++\sim+++$ & $5.69 \pm 1.63$ & $0.72 \pm 0.30$ & $17.77 \pm 6.61$ & $2.07 \pm 1.16$ \\
\hline 40 & III & T2NOMO & ductal & - & - & - & $++\sim+++$ & $5.64 \pm 1.33$ & $0.41 \pm 0.19$ & $12.36 \pm 4.50$ & $0.40 \pm 0.05$ \\
\hline 77 & III & T2NOMO & ductal & - & - & - & - & $3.90 \pm 0.79$ & $1.52 \pm 0.16$ & $6.97 \pm 1.66$ & $0.81 \pm 0.35$ \\
\hline
\end{tabular}



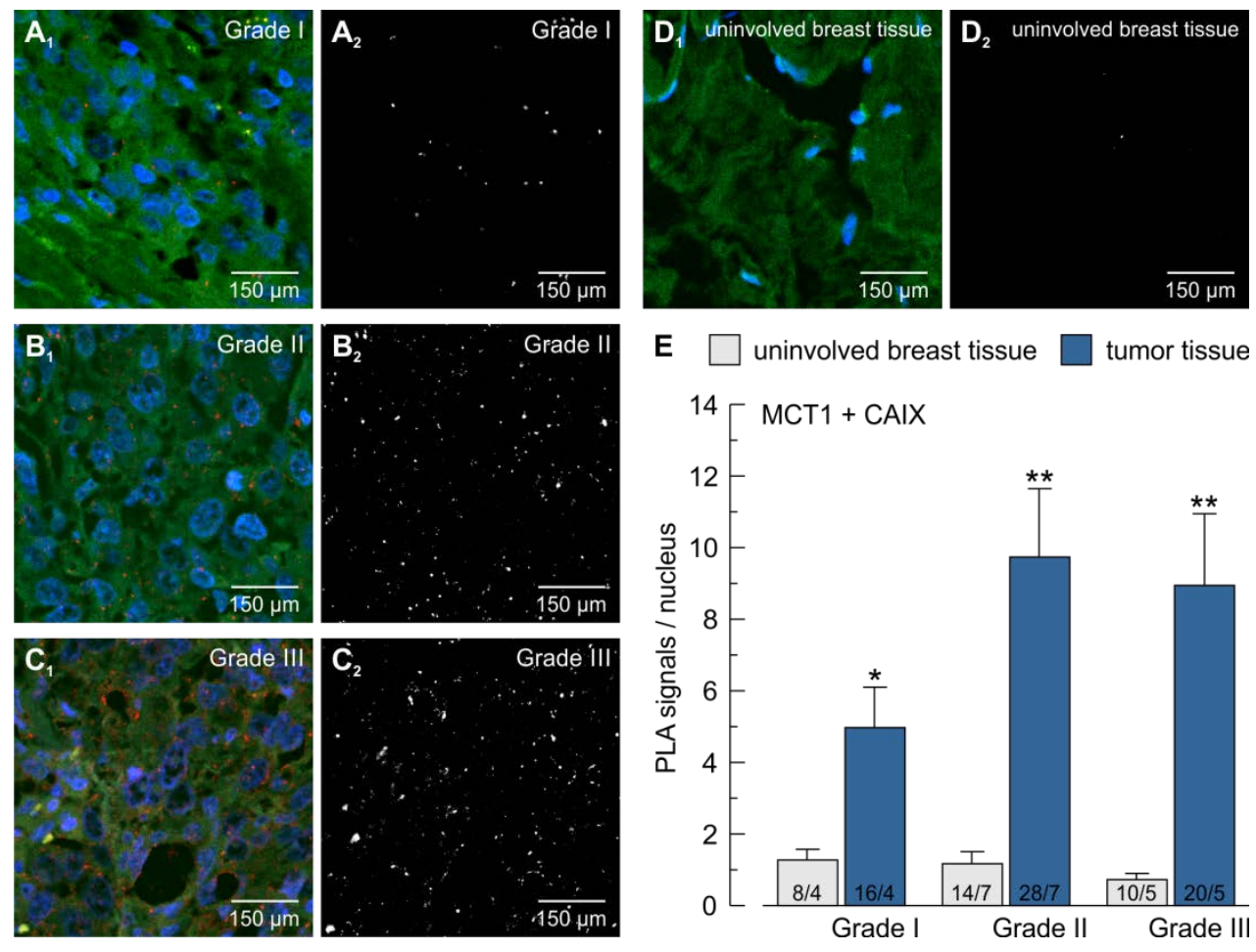

Figure 1: CAIX is colocalized with MCT1 in human breast tumor tissue, but not in healthy breast tissue. (A-D) In situ proximity ligation assay (PLA) for CAIX and MCT1 in grade I (A), grade II (B), and grade III (C) breast tumor tissue, and uninvolved breast tissue (D) of human cancer patients. Panels $A_{1}, B_{1}, C_{1}$, and $D_{1}$ show the PLA signals (red), nuclei staining (blue) and actin staining (green). Panels $A_{2}, B_{2}, C_{2}$, and $D_{2}$ show exclusively the PLA signals. (E) Quantification of the PLA signals per nucleus. The asterisks above the bars for tumor tissue refer to the corresponding bars for uninvolved breast tissue. 

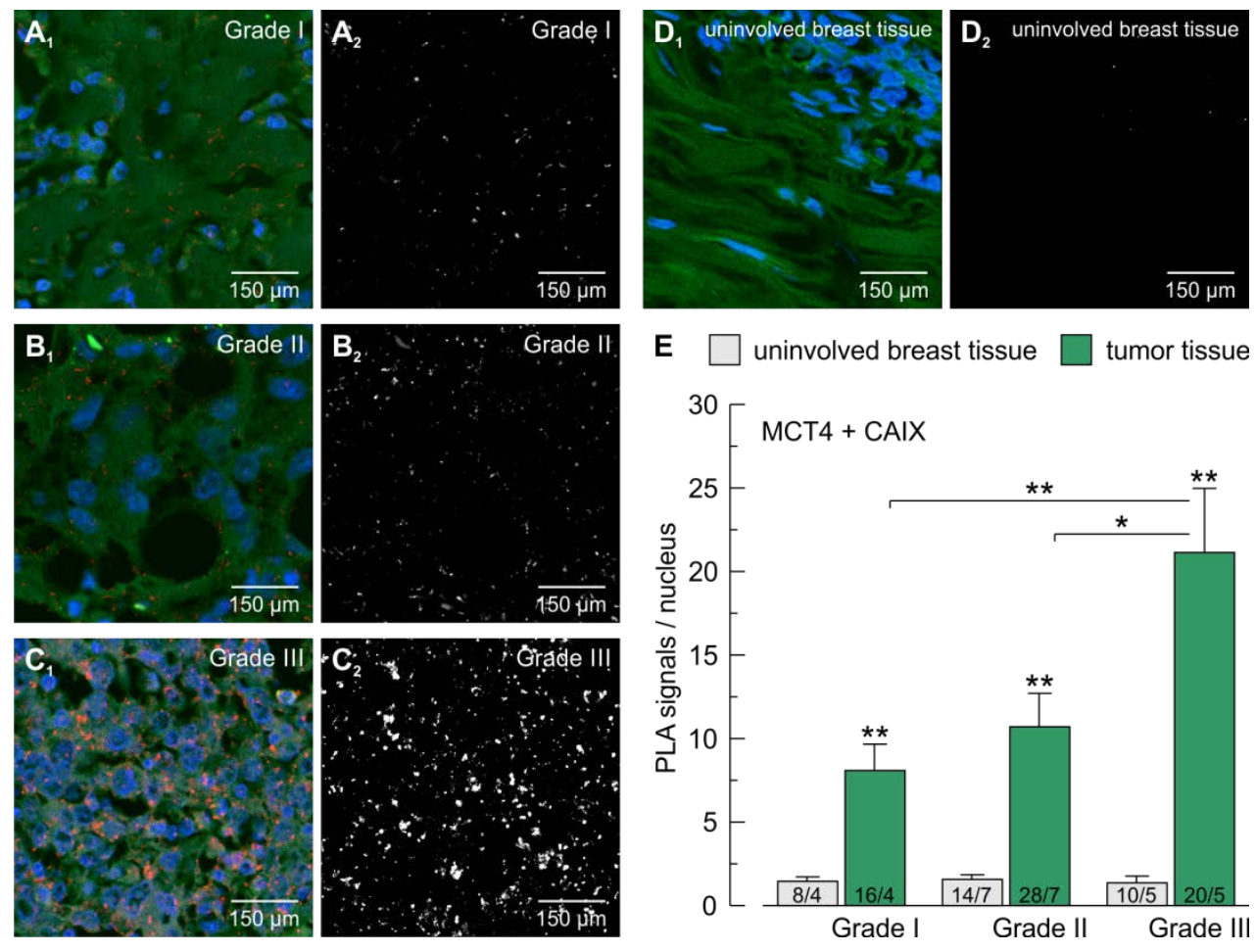

Figure 2: CAIX is colocalized with MCT4 in human breast tumor tissue, but not in healthy breast tissue. (A-D) In situ proximity ligation assay (PLA) for CAIX and MCT4 in grade I (A), grade II (B), and grade III (C) breast tumor tissue, and uninvolved breast tissue (D) of human cancer patients. Panels $A_{1}, B_{1}, C_{1}$, and $D_{1}$ show the PLA signals (red), nuclei staining (blue) and actin staining (green). Panels $A_{2}, B_{2}, C_{2}$, and $D_{2}$ show exclusively the PLA signals. (E) Quantification of the PLA signals per nucleus. The asterisks above the bars for tumor tissue refer to the corresponding bars for uninvolved breast tissue. 

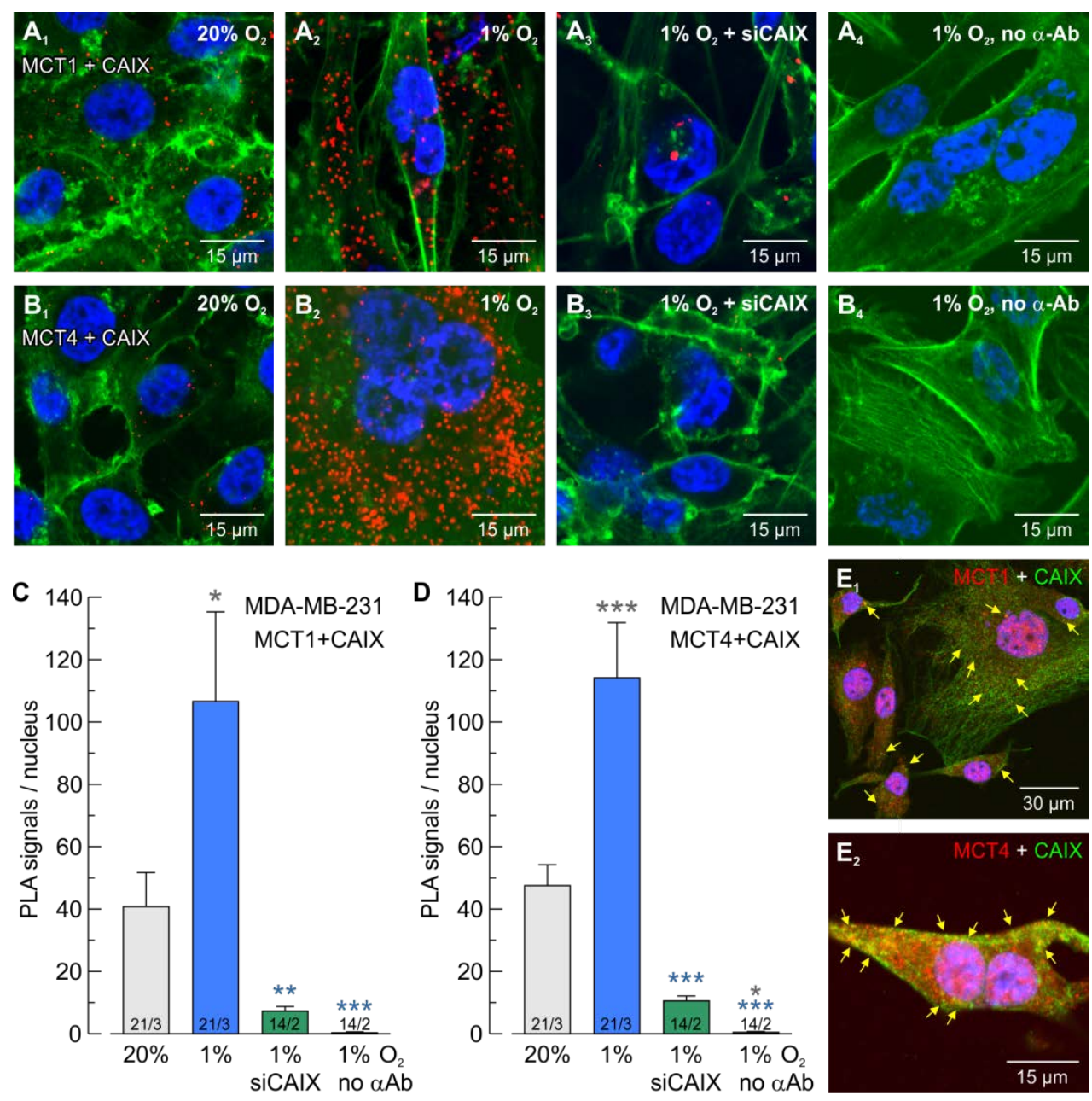

Figure 3: CAIX is colocalized with MCT1 and MCT4 in hypoxic MDA-MB-231 breast cancer cells. (A, B) In situ proximity ligation assay (PLA) for CAIX + MCT1 (A) and CAIX + MCT4 (B), respectively, in normoxic $\left(\mathbf{A}_{1}, \mathbf{B}_{1}\right)$ and hypoxic $\left(\mathbf{A}_{2}, \mathbf{B}_{2}\right)$ MDA-MB-231 cells. For control CAIX was knocked down with siRNA $\left(\mathbf{A}_{3}, \mathbf{A}_{4}\right)$ or the PLA was performed without primary antibodies $\left(\mathbf{A}_{4}, \mathbf{B}_{4}\right)$. PLA signals are shown in red, nuclei in blue and actin in green. (C, D) Quantification of the PLA signals for CAIX + MCT1 (C) and CAIX + MCT4 (D), respectively. The asterisks of a given color refer to the bars of the corresponding color. (E) Antibody staining for CAIX (green) and $\operatorname{MCT1}\left(\mathbf{E}_{1}\right.$, red) and $\operatorname{MCT} 4\left(\mathbf{E}_{2}\right.$, red), respectively, in hypoxic MDA-MB-231 cells. Nuclei are shown in blue. 

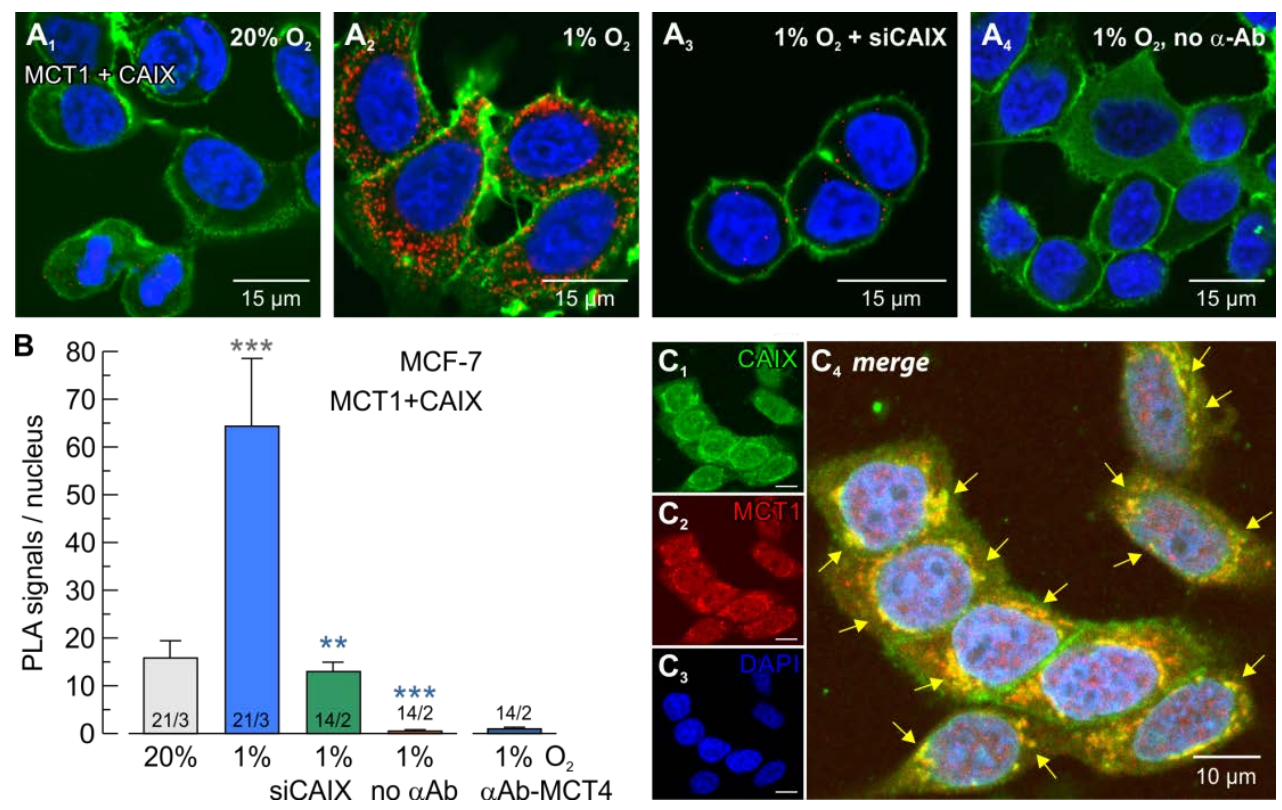

Figure 4: CAIX is colocalized with MCT1 in hypoxic MCF-7 breast cancer cells. (A) In situ proximity ligation assay (PLA) for CAIX and MCT1 in normoxic $\left(\mathbf{A}_{1}\right)$ and hypoxic $\left(\mathbf{A}_{2}\right)$ MCF-7 cells. For control CAIX was knocked down with siRNA $\left(\mathbf{A}_{\mathbf{3}}\right)$ or the PLA was performed without primary antibodies $\left(\mathbf{A}_{4}\right)$. PLA signals are shown in red, nuclei in blue and actin in green. (B) Quantification of the PLA signals for CAIX and MCT1. The asterisks of a given color refer to the bars of the corresponding color. (C) Antibody staining for CAIX $\left(\mathbf{C}_{1}\right.$, green), MCT1 $\left(\mathbf{C}_{2}\right.$, red) and nuclei $\left(\mathbf{C}_{3}\right.$, blue). $\mathbf{C}_{4}$ : Overlay of signals shown in $\mathrm{C}_{1-3}$. 


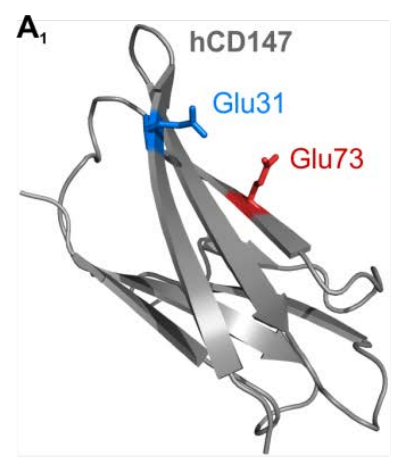

$\mathbf{A}_{2}$

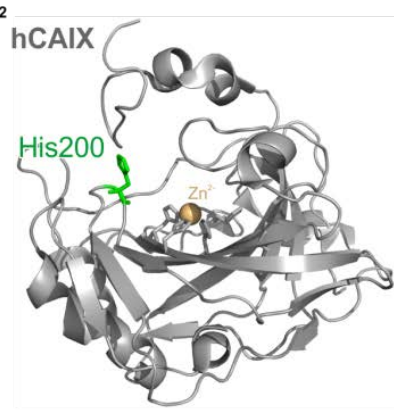

B

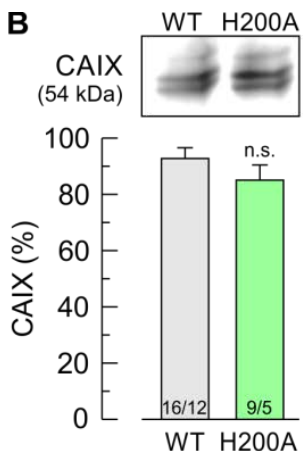

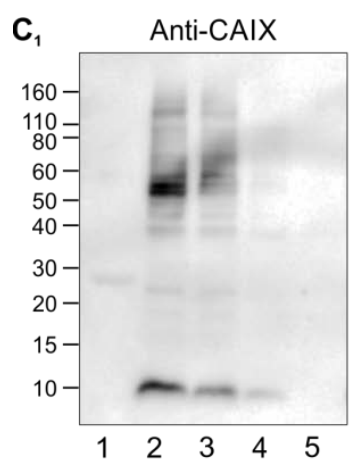
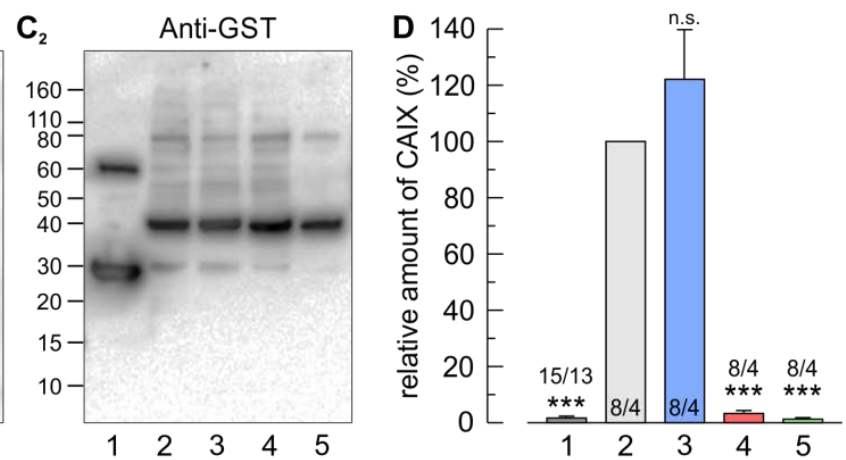

1 GST + CAIX 2 GST-hCD147-WT + CAIX 3 GST-hCD147-E31Q + CAIX 4 GST-hCD147-E73Q + CAIX 5 GST-hCD147-WT + CAIX-H200A

Figure 5: CAIX binds to the Ig1 domain of the MCT1/4 chaperon CD147. (A) Structure of the Ig1 domain of $\left(\mathbf{A}_{1}\right)$ human CD147 (PDB-ID: 3B5H [89]) and $\left(\mathbf{A}_{2}\right)$ human CAIX (PDB-ID: 4ZAO [90]). The putative binding sites (hCD147-E31, hCD147-E73 and CAIX-H200) are color labelled. (B) Western blot against CAIX from oocytes expressing CAIX-WT or CAIX-H200A. The antibody recognizes both WT and mutant equally well. (C) Representative western blots for CAIX $\left(\mathbf{C}_{1}\right)$ and GST $\left(\mathbf{C}_{2}\right)$. CAIX-WT and CAIXH200A, respectively, was pulled down with a GST fusion protein of the Ig1 domain of hCD147-WT or a mutant of the protein. (D) Relative fluorescent signal of CAIX. For every blot, the signals for CAIX were normalized to the corresponding signals for GST-hCD147-WT. Each individual signal for CAIX was normalized to the intensity of the signal for GST in the same lane. Mutation of CAIX-H2OO and hCD147-E73, but not hCD147-E31, abolishes binding between CAIX and hCD147. 
A

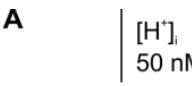

$$
\frac{\left[\mathrm{H}^{+}\right]_{\mathrm{i}}}{50 \mathrm{nM}}
$$

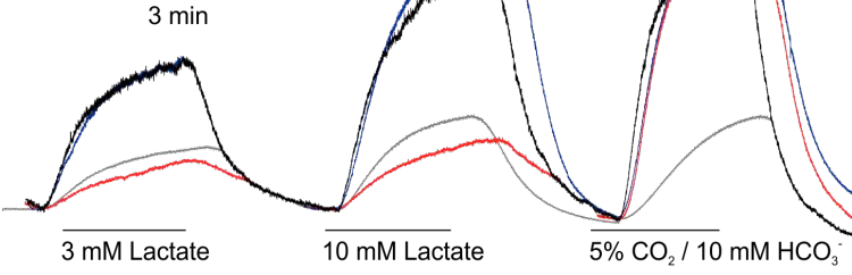

MCT1 + rCD147-WT

MCT1 + rCD147-E32A + CAIX

MCT1 + rCD147-WT + CAIX MCT1 + rCD147-K73A + CAIX

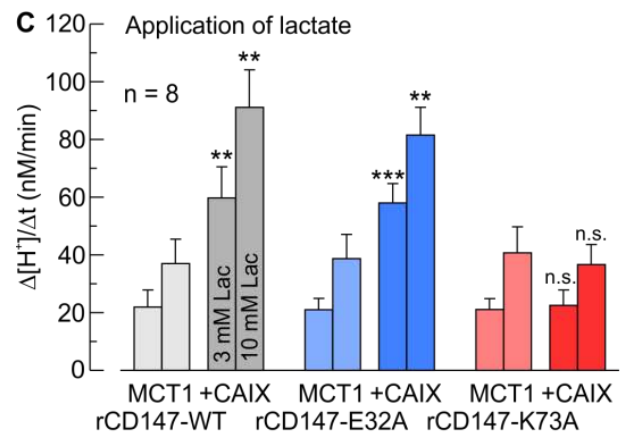

D -140 Removal
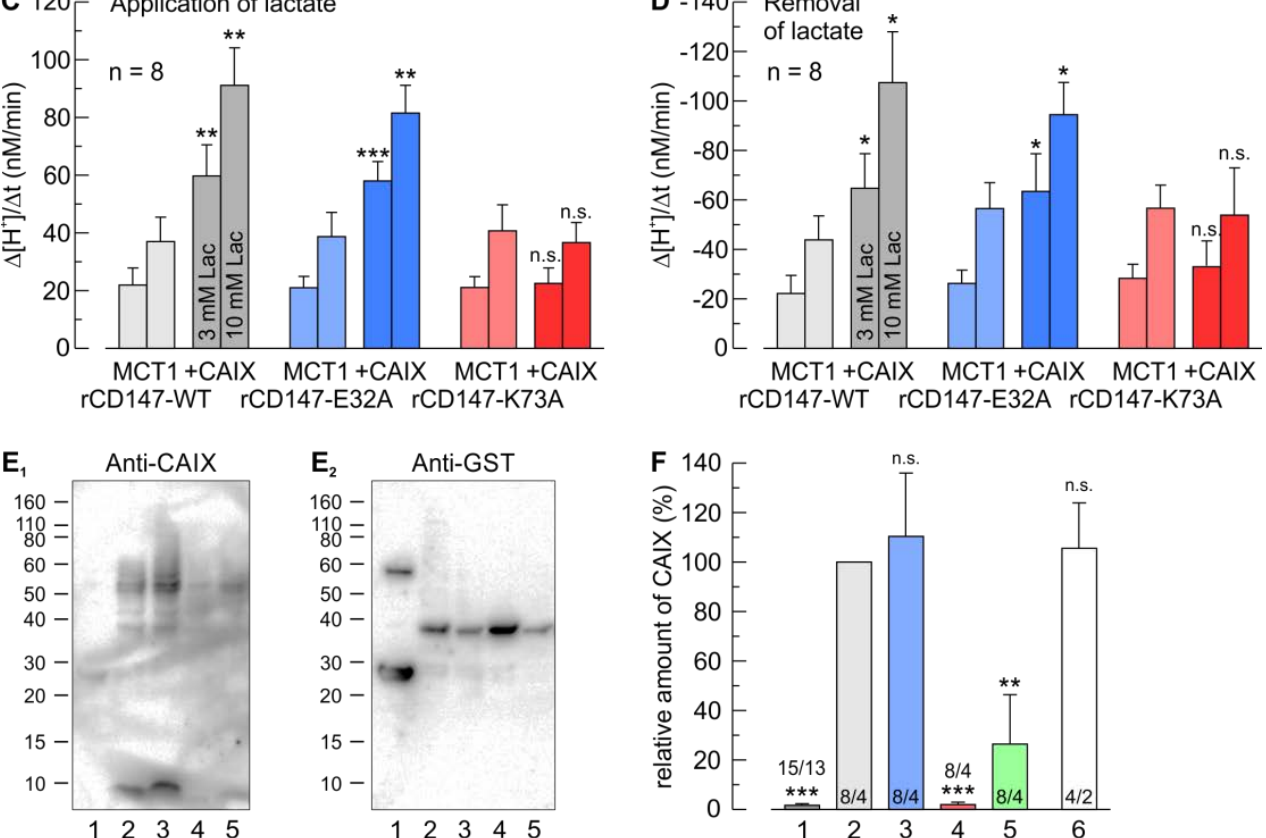

1 GST + CAIX 2 GST-rCD147-WT + CAIX

4 GST-rCD147-K73A + CAIX
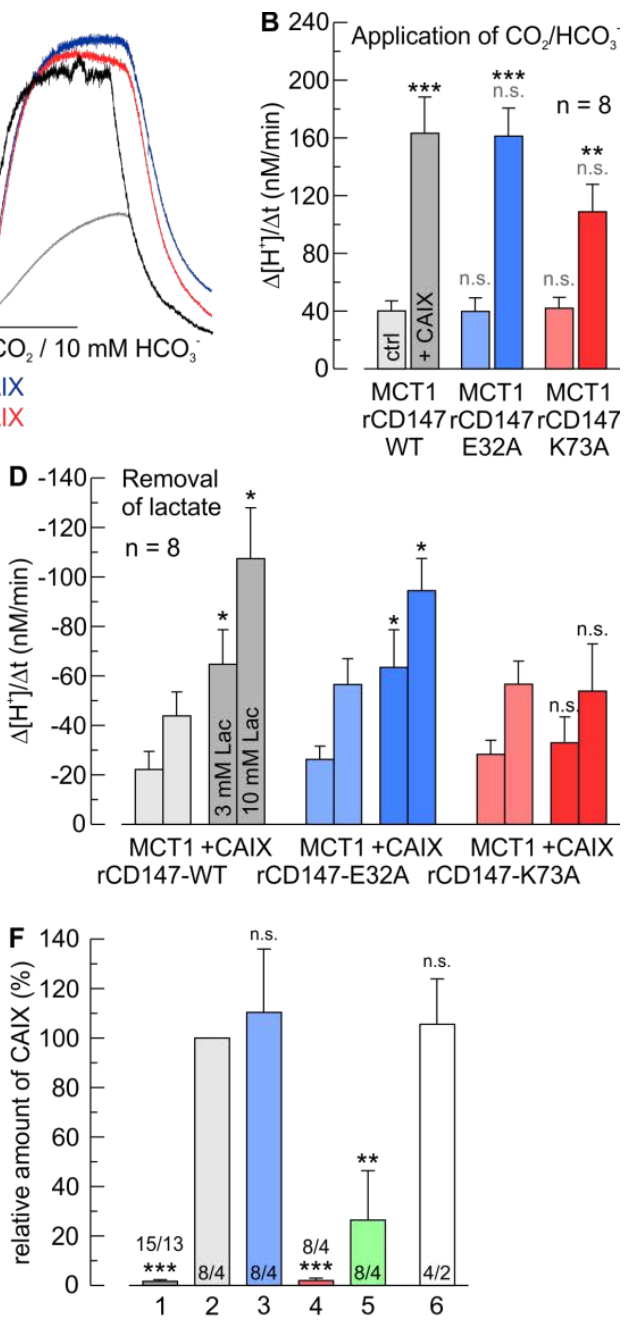

3 GST-rCD147-E32A + CAIX

Figure 6: CAIX-mediated facilitation of MCT1 transport activity requires binding of CAIX to the CD147 Ig1 domain. (A) Original recordings of the change in intracellular $\mathrm{H}^{+}$concentration during application of lactate and $\mathrm{CO}_{2} / \mathrm{HCO}_{3}{ }^{-}$in Xenopus oocytes, expressing $\mathrm{rMCT} 1$ together with $\mathrm{rCD} 147-$ WT (gray traces), rCD147-E32A (blue traces) or rCD147-K73A (red traces), either without (light traces) or with CAIX (dark traces). (B-D) Rate of change in intracellular $\mathrm{H}^{+}$concentration $\left(\Delta\left[\mathrm{H}^{+}\right] / \Delta \mathrm{t}\right)$ during application of $5 \% \mathrm{CO}_{2} / 10 \mathrm{mM} \mathrm{HCO}_{3}^{-}$(B) and application (C) and removal of lactate (D) in Xenopus oocytes, expressing rMCT1 together with rCD147-WT (gray bars), rCD147-E32A (blue bars), or rCD147-K73A (red bars), either without (light bars) or with CAIX (dark bars). The asterisks above the bars for CAIX-expressing cells refer to the corresponding bars for non-CAIX-expressing oocytes. Mutation of rCD147-K73, but not rCD147-E32, abolishes CAIX-mediated facilitation of MCT1 transport activity. (E) Representative western blots for CAIX $\left(E_{1}\right)$ and GST $\left(E_{2}\right)$. CAIX-WT and CAIXH200A, respectively, was pulled down with a GST fusion protein of the Ig1 domain of hCD147-WT or a mutant of the protein. (F) Relative fluorescent signal of CAIX. For every blot, the signals for CAIX were normalized to the corresponding signals for GST-rCD147-WT. Each individual signal for CAIX was normalized to the intensity of the signal for GST in the same lane. Mutation of CAIX-H200 and rCD147-K73, but not rCD147-E32, abolishes binding between CAIX and rCD147. The CAIX-PG domain is not involved in binding to CD147, since the truncation mutant CAIX- $\triangle P G$ binds GST-rCD147 equally well as CAIX-WT. 
A

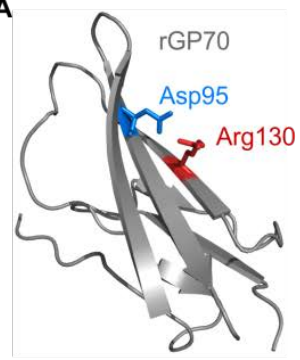

B

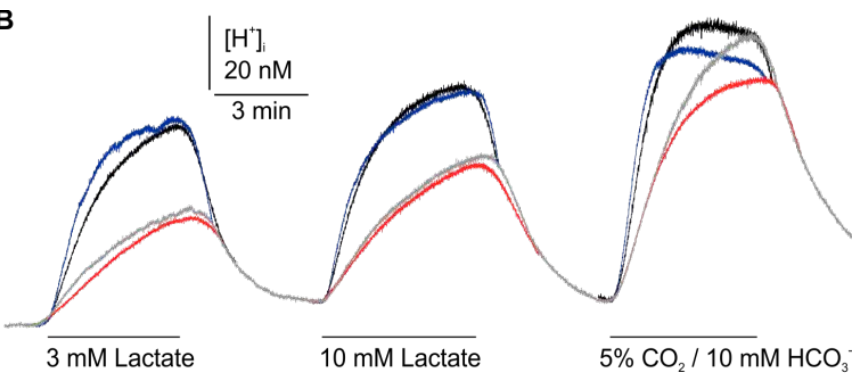

MCT1 + rGP70-WT + CAIX MCT1 + rGP70-D95A + CAIX MCT1 + rGP70-R130A + CAIX

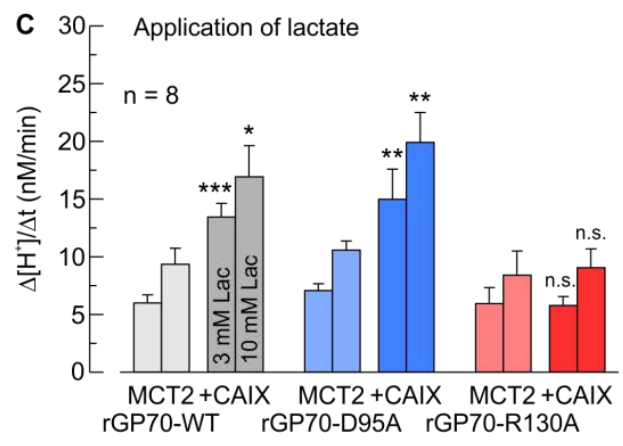

D ${ }^{-30}[$ Removal of lactate
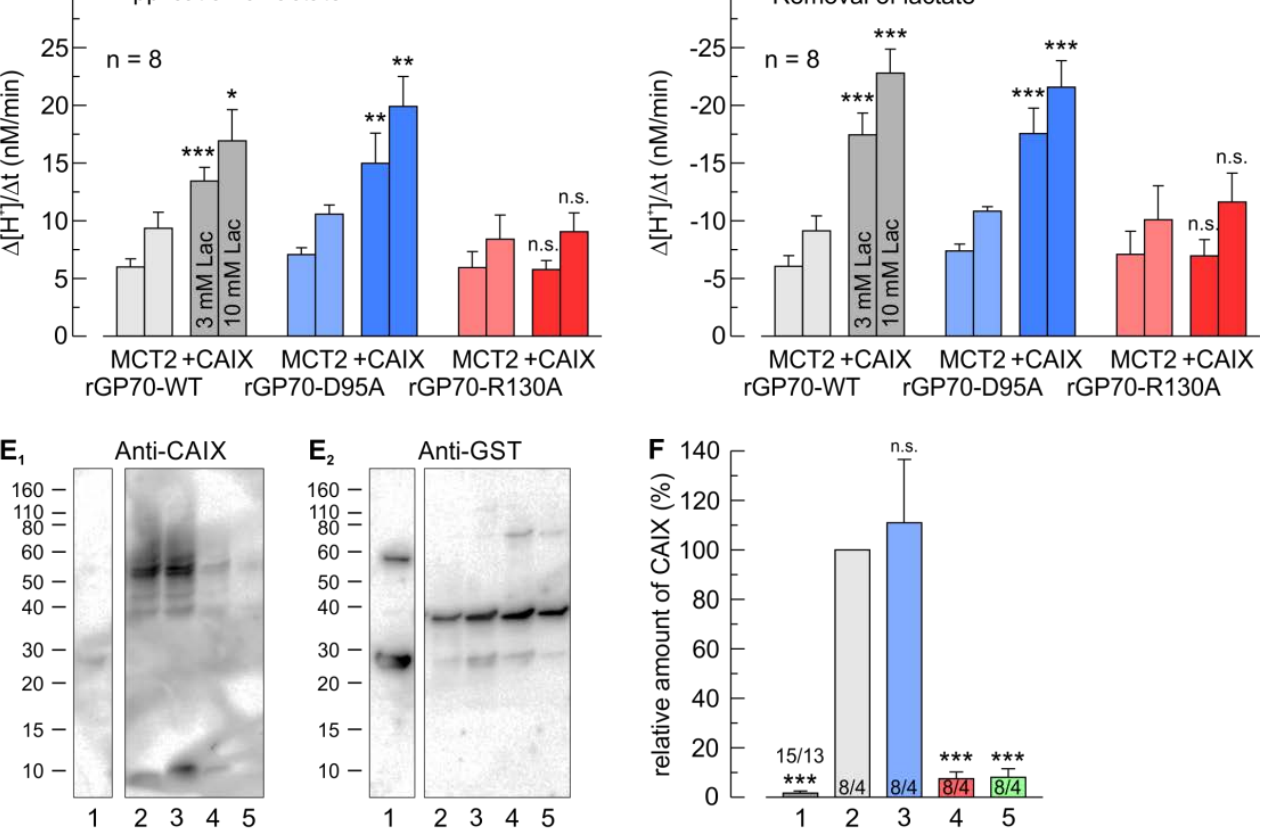

1 GST + CAIX 2 GST-rGP70-WT + CAIX 3 GST-rGP70-D95A + CAIX
4 GST-rGP70-R130A + CAIX 5 GST-rGP70-WT + CAIX-H200A

Figure 7: CAIX-mediated facilitation of MCT2 transport activity requires binding of CAIX to the Ig1 domain of the MCT2 chaperon GP70. (A) Homology structure of the Ig1 domain of rat GP70 (based on human CD147 (PDB-ID: 3B5H [89])). The putative CAIX binding sites (GP70-D95 and GP70-R130) are color labelled. (B) Original recordings of the change in intracellular $\mathrm{H}^{+}$concentration during application of lactate and $\mathrm{CO}_{2} / \mathrm{HCO}_{3}{ }^{-}$in Xenopus oocytes, expressing $\mathrm{rMCT} 2$ together with $\mathrm{rGP70}-\mathrm{WT}$ (gray traces), rGP70-D95A (blue traces), or rGP70-R130A (red traces), either without (light traces) or with CAIX (dark traces). (C, D) Rate of change in intracellular $\mathrm{H}^{+}$concentration $\left(\Delta\left[\mathrm{H}^{+}\right] / \Delta \mathrm{t}\right)$ during application (C) and removal of lactate (D) in Xenopus oocytes, expressing $\mathrm{rMCT2}$ together with rGP70-WT (gray bars), rGP70-D95A (blue bars), or rGP70R130A (red bars), either without (light bars) or with CAIX (dark bars). The asterisks above the bars for CAIX-expressing cells refer to the corresponding bars for non-CAIX-expressing oocytes. Mutation of rGP70-R130, but not D95, abolishes CAIX-mediated facilitation of MCT2 transport activity. (E) Representative western blots for CAIX (upper blot) and GST (lower blot). CAIX-WT and CAIX-H200A, respectively was pulled down with a GST fusion protein of the Ig1 domain of rGP70-WT or a mutant of the protein. (F) Relative fluorescent signal of CAIX. For every blot, the signals for CAIX were normalized to the corresponding signals for GST-rGP70-WT. Each individual signal for CAIX was normalized to the intensity of the signal for GST in the same lane. Mutation of CAIX-H200 and rGP70-R130, but not rGP70-D95, abolishes binding between CAIX and rGP70. 

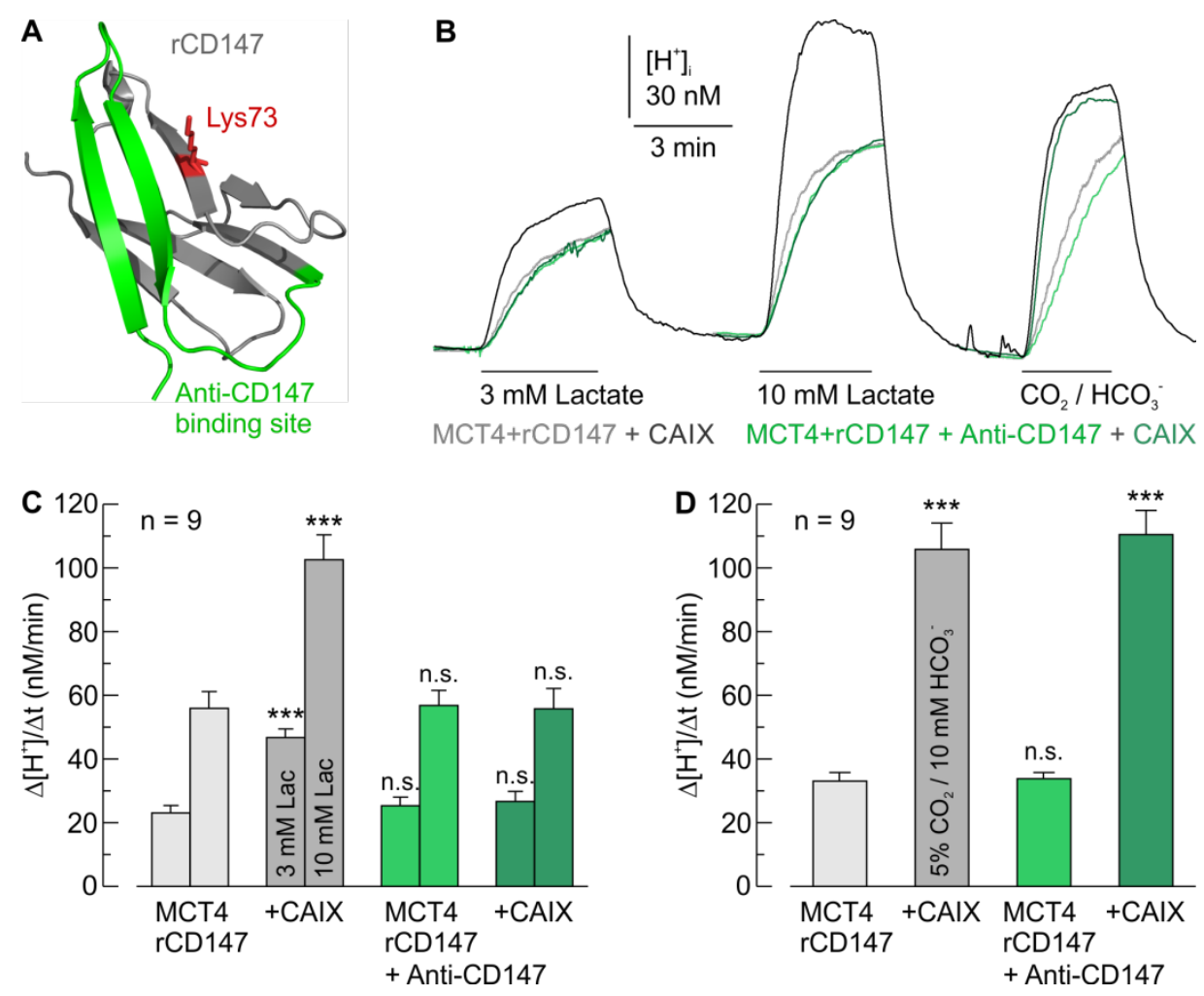

Figure 8: CAIX-mediated facilitation of MCT4 transport activity is disrupted by an antibody against the Ig1 domain of CD147. (A) Structure of the Ig1 domain of rat CD147 (PDB-ID: 3B5H [89]). The CAIX binding site $\mathrm{K} 73$ is labelled in red. The antibody binding region is labelled in green. (B) Original recordings of the change in intracellular $\mathrm{H}^{+}$concentration during application of lactate and $\mathrm{CO}_{2} / \mathrm{HCO}_{3}{ }^{-}$ in rMCT4+rCD147-WT-coexpressing Xenopus oocytes, pre-incubated without (gray traces) or with an antibody against CD147 (Anti-CD147; green traces), either without (light traces) or with CAIX (dark traces). (C, D) Rate of change in intracellular $\mathrm{H}^{+}$concentration $\left(\Delta\left[\mathrm{H}^{+}\right] / \Delta \mathrm{t}\right)$ during application of lactate (C) and $5 \% \mathrm{CO}_{2} / 10 \mathrm{mM} \mathrm{HCO}_{3}^{-}$(D), respectively, in rMCT4+rCD147-WT-coexpressing Xenopus oocytes, pre-incubated without (gray bars) or with Anti-CD147 (green bars), either without (light bars) or with CAIX (dark bars). The significance indicators refer to the bars for MCT4+rCD147expressing oocytes. 

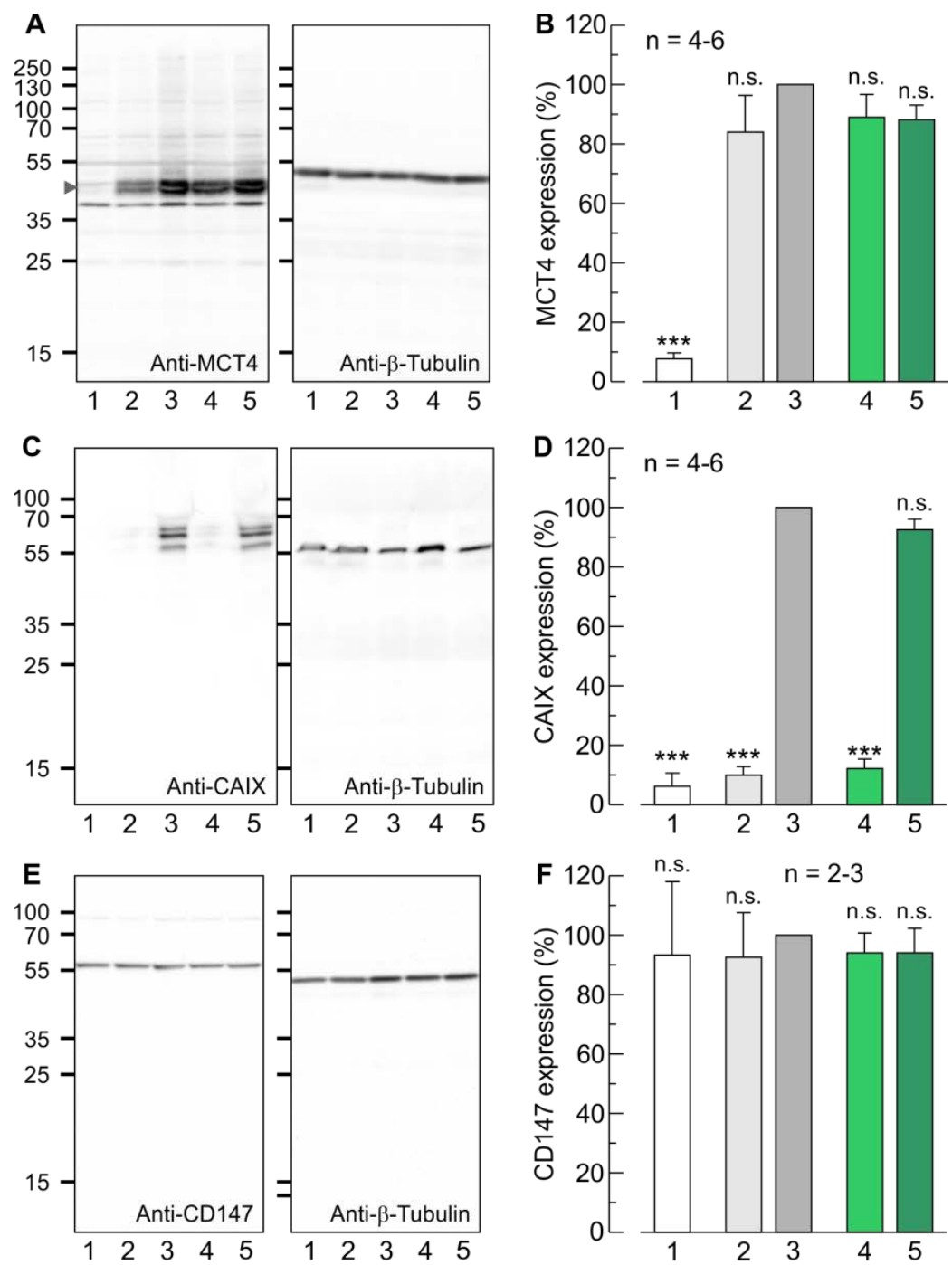
1 Native 2 MCT4 + CD147
3 MCT4 + CD147 + CAIX
4 MCT4 + CD147 + Anti-CD147
5 MCT4 + CD147 + CAIX + Anti-CD147

Figure 9: Control of protein expression in MCT4+rCD147 \pm CAIX-expressing oocytes, pre-incubated with or without Anti-CD147. (A, C, E) Representative western blots against MCT4 (A), CAIX (B), and CD147 (C) and corresponding staining against $\beta$-tubulin (left blots) from oocytes expressing MCT4+CD147 $\pm C A I X$, pre-incubated with Anti-CD147 or not, and native oocytes as control. (B, D, F) Relative fluorescent signal of MCT4 (B), CAIX (D), and CD147 (F). For every lane, the signals were normalized to the corresponding signals for $\beta$-tubulin. For every blot the signals were normalized to the signal for MCT4+CD147+CAIX-expressing oocytes. 

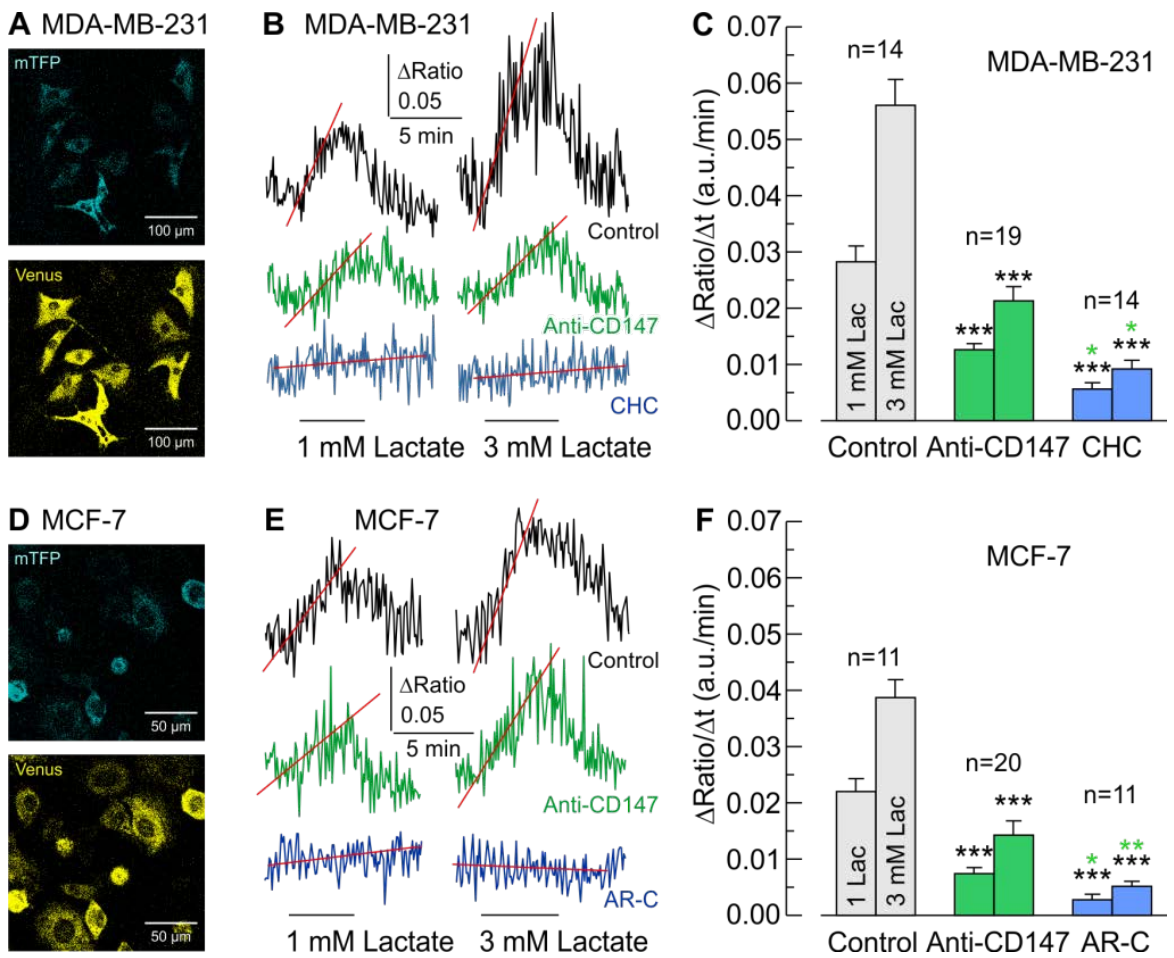

Figure 10: Anti-CD147 reduces lactate transport capacity in hypoxic breast cancer cells. (A, D) Fluorescent signals for mTFP (460-500 nm) (upper panel, blue) and Venus $(520-550 \mathrm{~nm}$ ) (lower panel, yellow) from MDA-MB-231 (A) and MCF-7 cells (D), transfected with the lactate-sensitive FRET nanosensor Laconic. (B, E) Original recordings of the relative change in intracellular lactate concentration during application of 1 and 3 mM lactate in hypoxic MDA-MB-231 (B) and MCF-7 cells (E), pre-incubated without (black and blue traces) or with Anti-CD147 (green traces), in the absence (black and green traces) or presence of the MCT inhibitors $\alpha$-cyano-4-hydroxycinnamate (CHC) or ARC155858 (blue traces). (C, F) Rate of change in lactate concentration ( $\triangle$ Ratio/ $\Delta \mathrm{t}$ ) during application of lactate in hypoxic MDA-MB-231 (C) and MCF-7 cells (F), pre-incubated without (black and blue bars) or with Anti-CD147 (green bars), in the absence (black and green bars) or presence of CHC or AR-C (blue bars). The asterisks of a given color refer to the bars of the corresponding color. 

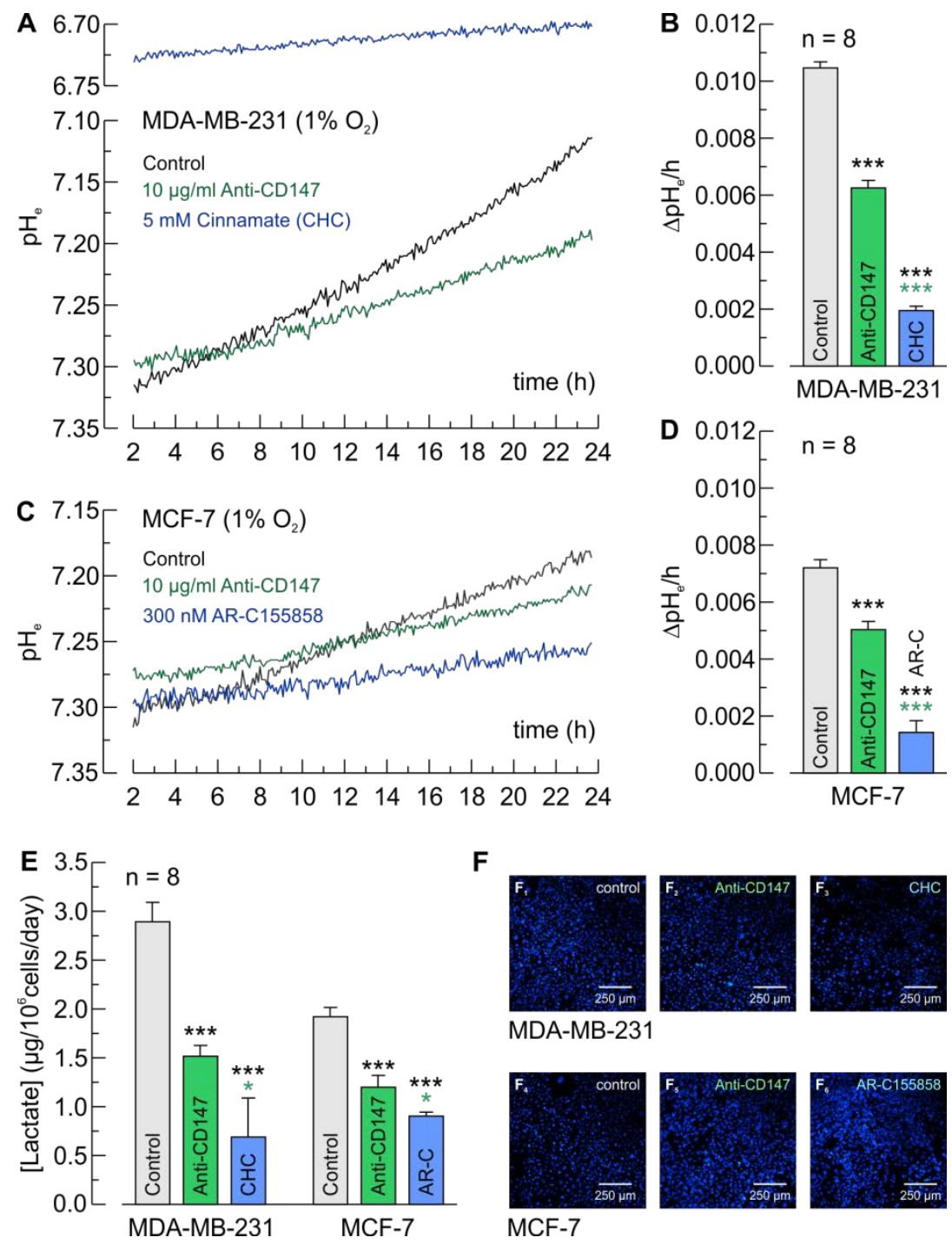

Figure 11: Anti-CD147 reduces glycolytic activity in hypoxic breast cancer cells. (A, C) Original recordings of extracellular $\mathrm{pH}$, as measured with a SensorDish Reader in the culture medium, in hypoxic MDA-MB-231 (A) and MCF-7 cells (C), pre-incubated without (black and blue traces) or with Anti-CD147 (green traces), in the absence (black and green traces) or presence of the MCT inhibitors $\alpha$-cyano-4-hydroxycinnamate (CHC) or AR-C155858 (blue traces). (B, D) Rate of change in extracellular $\mathrm{pH}(\Delta \mathrm{pH} / \mathrm{h})$ in hypoxic MDA-MB-231 (B) and MCF-7 cells (D), pre-incubated without (black and blue bars) or with Anti-CD147 (green bars), in the absence (black and green bars) or presence of $\mathrm{CHC}$ or AR-C (blue bars). The asterisks of a given color refer to the bars of the corresponding color. (E) Lactate production (in $\mu \mathrm{g}$ of lactate $/ 10^{6}$ cells/day), as measured with an enzymatic assay in the culture medium of hypoxic MDA-MB-231 and MCF-7 cells, pre-incubated without (black and blue bars) or with Anti-CD147 (green bars), in the absence (black and green bars) or presence of $\mathrm{CHC}$ or $\mathrm{AR}-\mathrm{C}$ (blue bars). The asterisks of a given color refer to the bars of the corresponding color. (F) Representative pictures of nuclei staining of the cells used for the lactate assay, shown in (E). For every batch of cells lactate concentration was normalized to the amount of cells. 

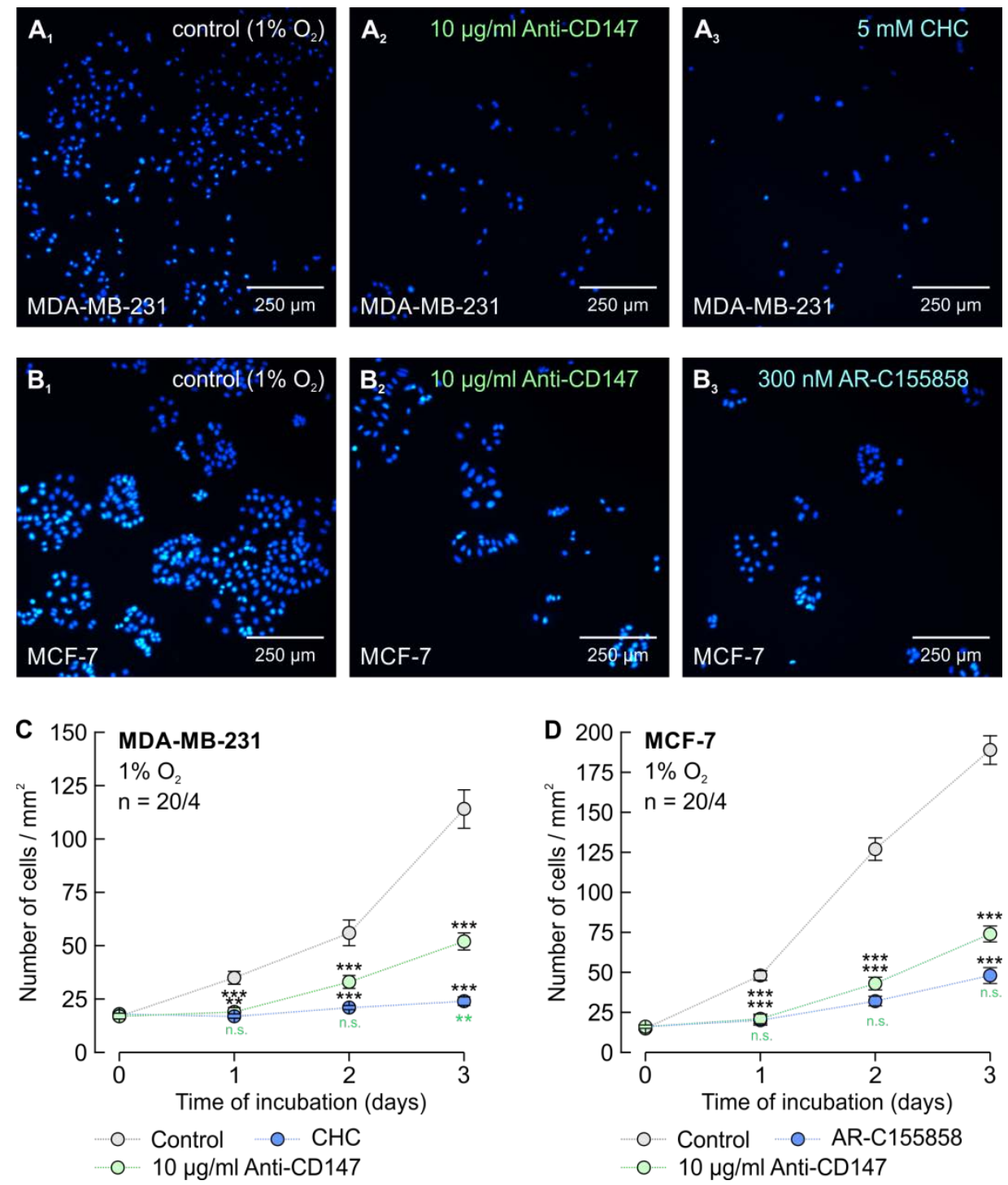

Figure 12: Application of $10 \mu \mathrm{g} / \mathrm{ml}$ of Anti-CD147 reduces proliferation of hypoxic breast cancer cells. (A, B) Staining of nuclei with Hoechst 33342 (blue) in MDA-MB-231 (A) MCF-7 cells (B), after 3 days in culture. Hypoxic cells remained either untreated $\left(\mathbf{A}_{1}, \mathbf{B}_{1}\right)$, incubated with $10 \mu \mathrm{g} / \mathrm{ml}$ Anti-CD147 $\left(\mathbf{A}_{2}, \mathbf{B}_{2}\right)$, or incubated with the MCT inhibitors $\alpha$-cyano-4-hydroxycinnamate $(\mathrm{CHC})$ or AR-C155858 $\left(\mathbf{A}_{3}\right.$, $\mathbf{B}_{3}$ ). (C, D) Total number of nuclei/mm in MDA-MB-231 (C) and MCF-7 cell cultures (D), kept for 0-3 days under the conditions described in (A, B). For every data point four dishes of cells were used and five pictures were taken from each dish at random locations, yielding 20 pictures/data point $(n=$ 20/4). 

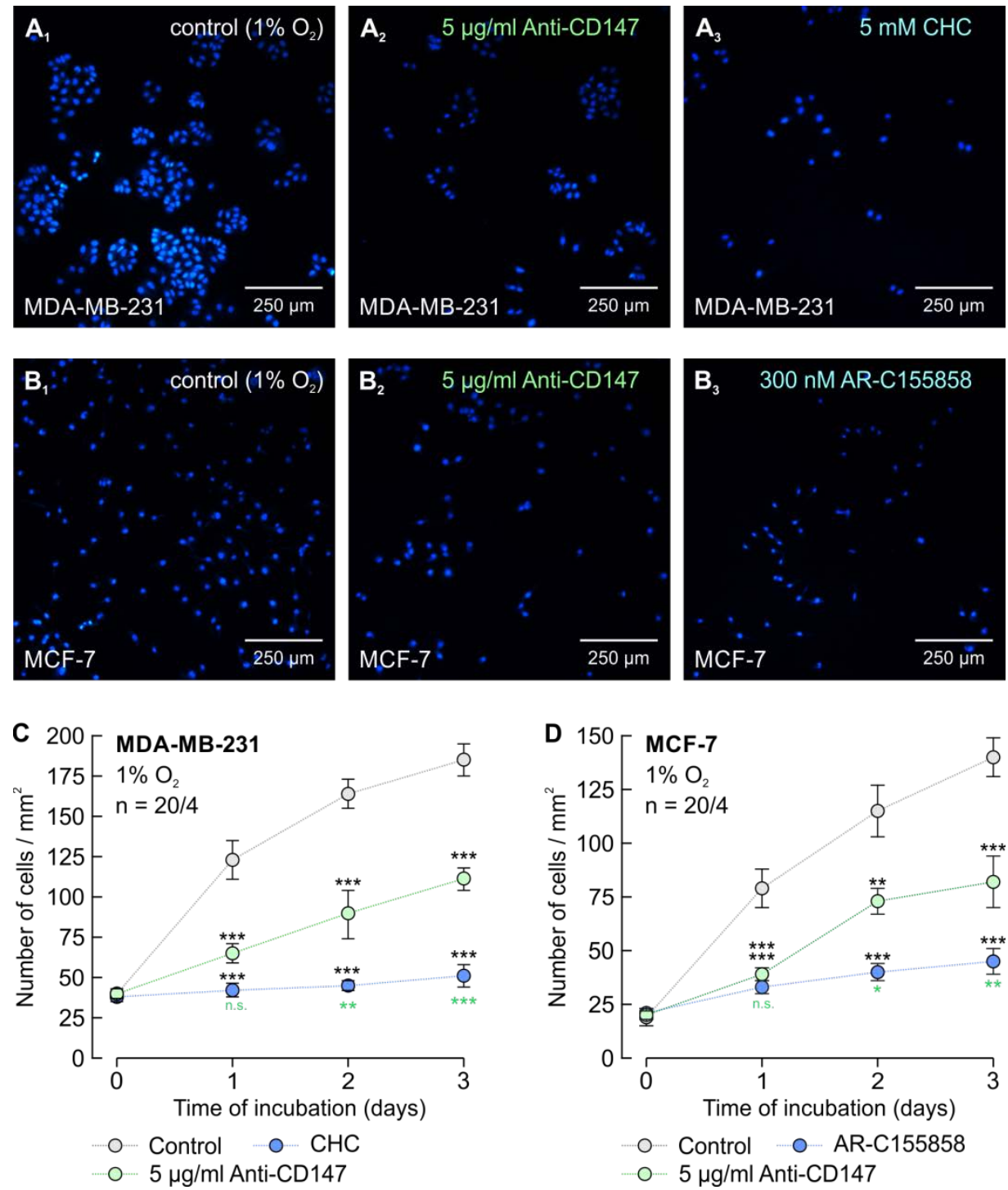

Figure 13: Application of $5 \mu \mathrm{g} / \mathrm{ml}$ of Anti-CD147 reduces proliferation of hypoxic breast cancer cells. (A, B) Staining of nuclei with Hoechst 33342 (blue) in MDA-MB-231 (A) MCF-7 cells (B), after 3 days in culture. Hypoxic cells remained either untreated $\left(\mathbf{A}_{1}, \mathbf{B}_{1}\right)$, incubated with $5 \mu \mathrm{g} / \mathrm{ml}$ Anti-CD147 $\left(\mathbf{A}_{\mathbf{2}}, \mathbf{B}_{\mathbf{2}}\right)$, or incubated with the MCT1 inhibitors $\alpha$-cyano-4-hydroxycinnamate (CHC) or AR-C155858 $\left(\mathbf{A}_{\mathbf{3}}, \mathbf{B}_{\mathbf{3}}\right)$. (C, D) Total number of nuclei/mm in MDA-MB-231 (C) and MCF-7 cell cultures (D), kept for 0-3 days under the conditions described in (A, B). For every data point four dishes of cells were used and five pictures were taken from each dish at random locations, yielding 20 pictures/data point $(n=$ 20/4). 


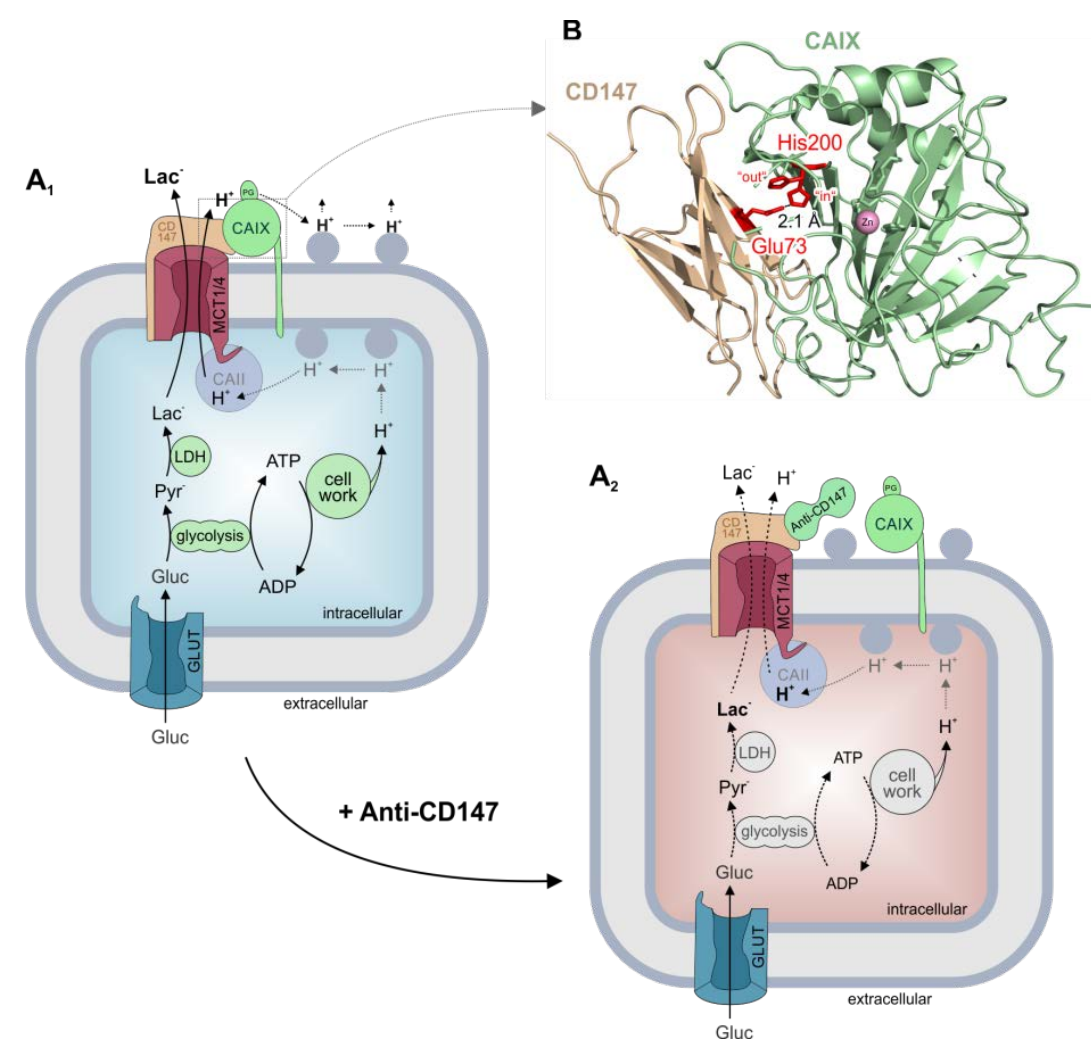

Figure 14: Model of the MCT1/4-CD147-CAIX transport metabolon. $\left(\mathbf{A}_{1}\right)$ Glycolysis serves as the prime energy source for hypoxic cancer cells, leading to vast production of lactate and protons which have to be removed from the cell to avoid intracellular acidosis and suffocation of cell metabolism. Under these conditions CAIX, which is directly bound to the Ig1 domain of the MCT1/4 chaperon $\mathrm{CD} 147$, serves as a proton antenna for the transporter which rapidly exchanges $\mathrm{H}^{+}$between transporter pore and surrounding protonatable residues (blue-gray circles) at the extracellular site of the plasma membrane. Fast removal of $\mathrm{H}^{+}$counteracts the formation of proton microdomains around the transporter pore and drives the efflux of lactate and protons from the cell. Cytosolic CAll, which is directly bound to the MCT1/4 C-terminal tail, serves as the intracellular counterpart to CAIX. CAll collects $\mathrm{H}^{+}$from surrounding protonatable residues at the inner face of the plasma membrane and shuttles them to the transporter pore. $\left(\mathbf{A}_{2}\right)$ Binding of Anti-CD147 to an epitope close to the CAIX binding site in the Ig1 domain of CD147, drives CAIX away from the MCT1/4-CD147 complex. This disruption of the transport metabolon leads in a decrease in MCT1/4 transport capacity, resulting in intracellular accumulation of lactate and protons, which in turn leads to a decrease in glycolytic activity and ultimately a reduction in cell proliferation. (B) Structural model of the physical interaction between CAIX and CD147. CAIX (green structure) binds to the Ig1 domain of CD147 (ochre structure) by formation of a hydrogen bond (dotted line) between CD147-Glu73 and CAIX-His200 in the "in" confirmation (red sticks), with a distance of $2.1 \AA$ A between the two binding partners. 